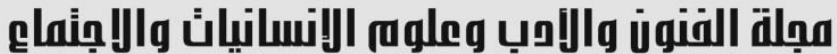

Journal of Arts, Literature, Humanities and Social Sciences www.jalhss.com

\section{درجة الاحتراق النفسي لاى معلمي المرحلة الابتدائية في المدارس الككومية الاردنية (دراسة تطبيقية)}

غيث احمد سعود العدوان البريد الاككتروني: gaithaladwan3@gmail.com

الاخمص

لقد هدفت هذه الدراسة لمعرفة درجة الاحتراق النفسي لدى معلمي المرحلة الابتدائية في المدارس الحكومية

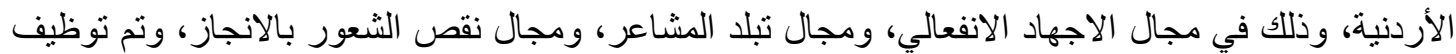
النهج الوصفي التحليلي. لتحقيق الغايات المقصودة من هذه الدراسة، عمل الباحث على اختيار عينة مكونة من 208 معلم ومعلمة من معلمي المرحلة الابندائية من ستة عشر (16) مدرسة من المدارس الحكومية الاردنية الو اقعة في عمان، والكرك والزرقاء واربد، حيث جرى اختيار أربعة مدارس من كل مدينة، ولقد تم اختيار هؤلاء المعلمين عن طريق الاسلوب الطبقي العشوائي، وجرى توزيع استمارات الاستبيان على الافراد المبحوثين عن طريق البريد الالكتروني، ونم استعادة 191 استمارة من المبحوثين صالحة للتحليل، وتمثلت نسبة الاسترداد بالنسبة الاتية: 81.82\%، وتم توظيف برنامج SPSS لغاية تحليل البيانات، وتبين ان درجة الاحتر اق النفسي لدى معلمي المرحلة الابتدائية في المدارس الحكومية الأردنية تعد منخفضة في جميع المجالات مجتمعة ومنفردة، ولقد أوصى الباحث بتزويد مقدارا اكبر من الدعم النفسي والاجنماعي للمعلمين في الأردن، حيث سينعكس ذلك إيجابا على مخرجات التعلم، وجودة التعليم المدرسي في الأردن. 


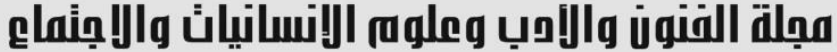

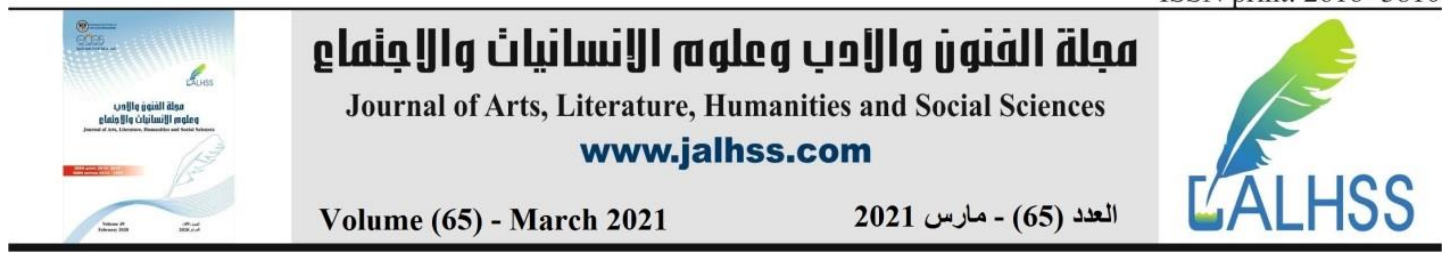

\section{The Psychological Burnout Level of Jordanian Public Primary School Teachers (An empirical study)}

\author{
Ghaith Ahmad Soud Al-Aduan \\ Jordan \\ Email: gaithaladwan3@gmail.com
}

\begin{abstract}
This study investigated the psychological burnout level of Jordanian public primary school teachers. It investigated that in in the following areas: (emotional exhaustion, depersonalization, and lack of personal accomplishment). A descriptive analytical approach is adopted to meeting the intended goals. The researcher selected 208 female and male primary teachers from 16 Jordanian public schools in Amman, Karak, Zarqa, and Irbid. From each city, 4 schools were selected. Those teachers were selected through the random stratified sampling method. Questionnaire forms were distributed those sampled teachers via email. 191 forms were retrieved and considered valid for analysis. The response rate is $91.82 \%$. SPSS software was employed. The researcher found that the psychological burnout level of Jordanian public primary school teachers is low in all the targeted areas jointly and separately. He recommends providing more psychological and social support to teachers in Jordan. That shall positively affect the learning outcomes and the quality of school education in Jordan.
\end{abstract}

Keywords: Psychological burnout, public schools, primary schools, Jordan. 


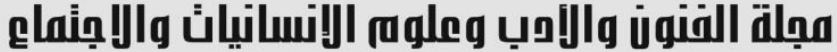

Journal of Arts, Literature, Humanities and Social Sciences www.jalhss.com

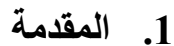

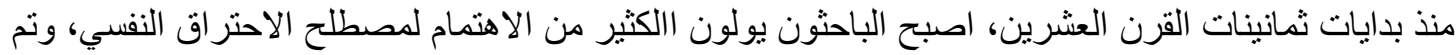

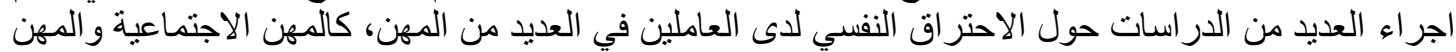

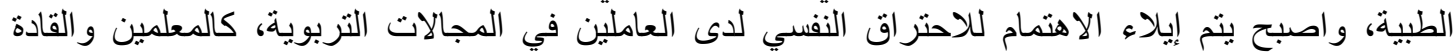

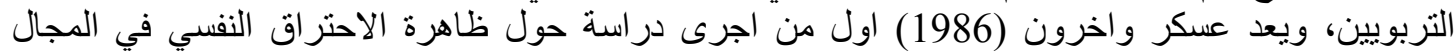
التربوي في العالم العربي (الحاتمي، 2014) الترون (1986) لقد حظيت ظاهرة الاحتراق النفسي ما بين صفوف التئ المعلمين بالكثير من الاهتمام، وذلك بسبب التحديات

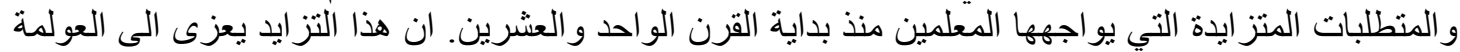

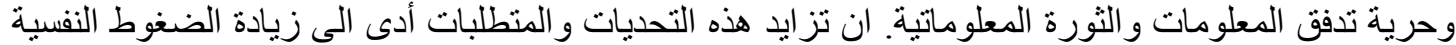

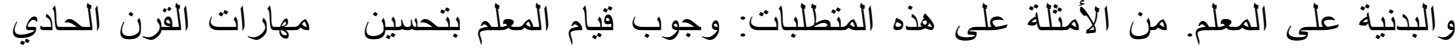

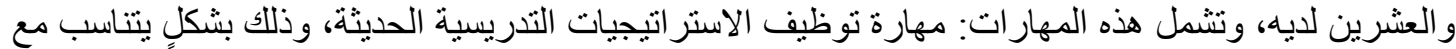

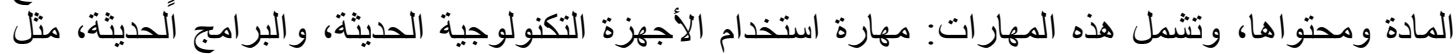

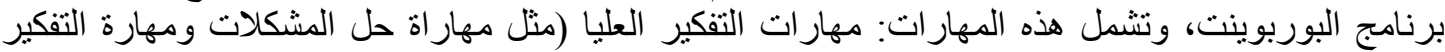

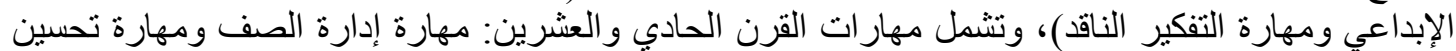

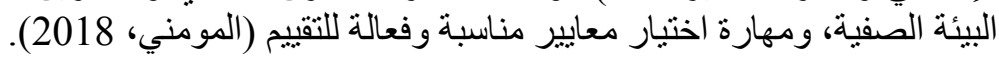

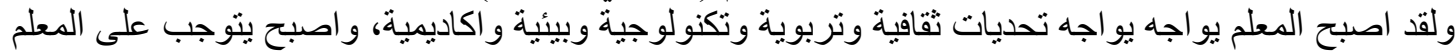

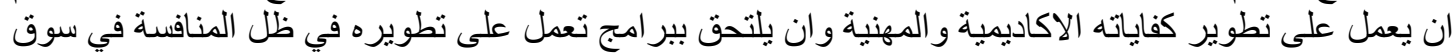

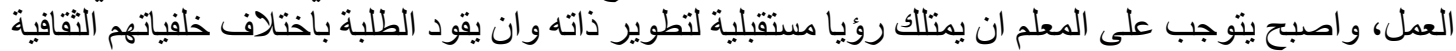

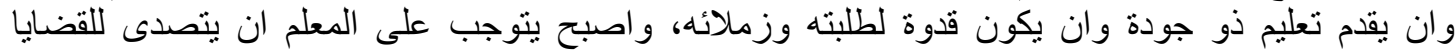

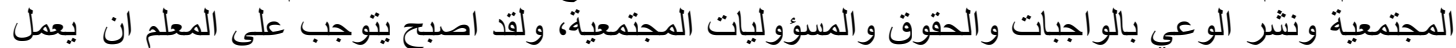

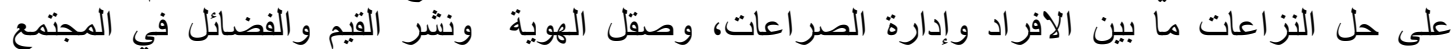

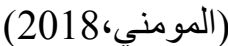

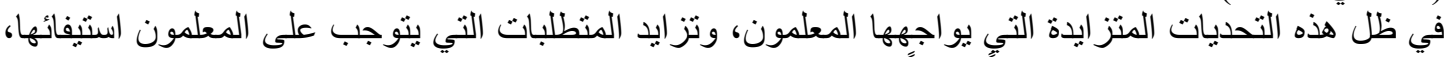

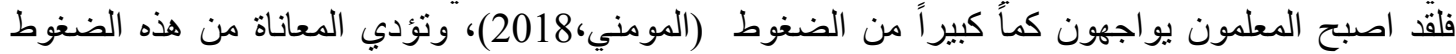

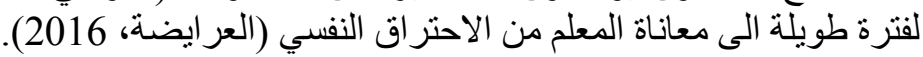

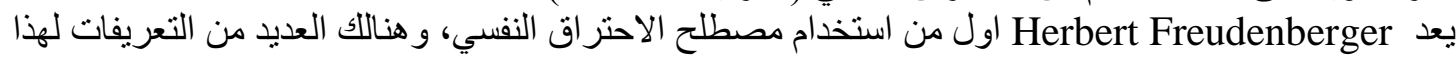

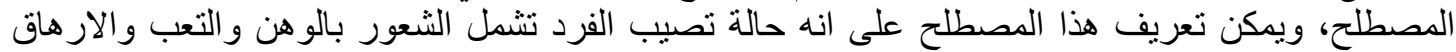

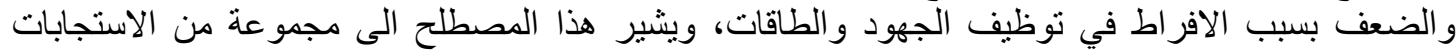

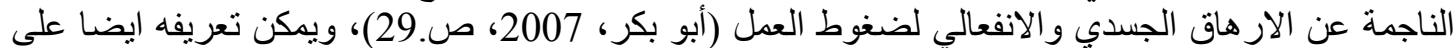

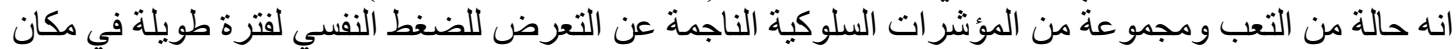
العمل (Branetti, 2001, 52)

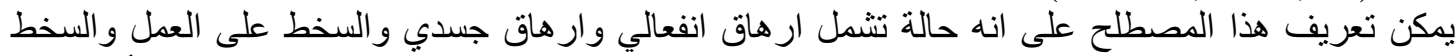

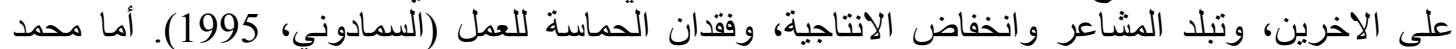

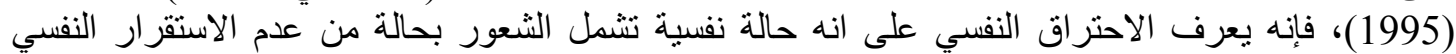

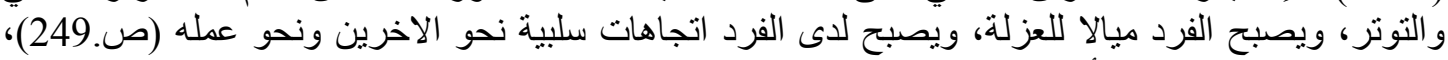

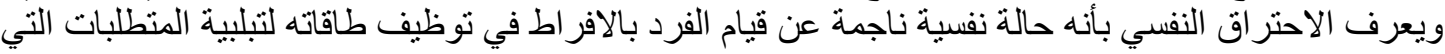

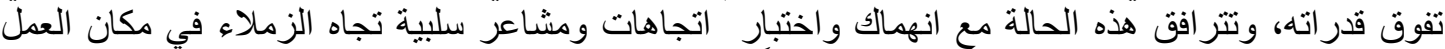

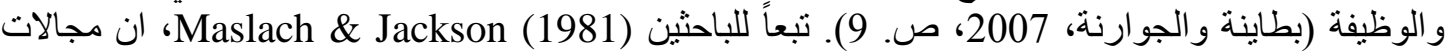

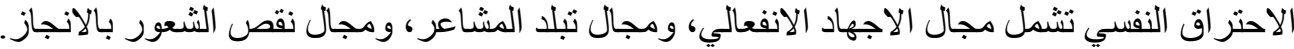

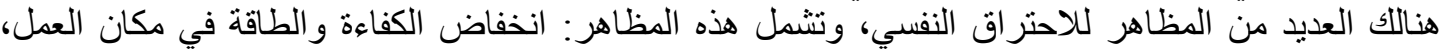

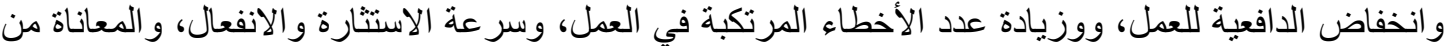

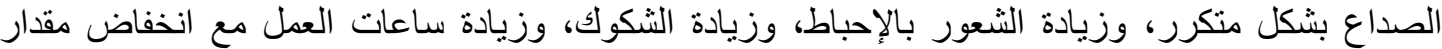

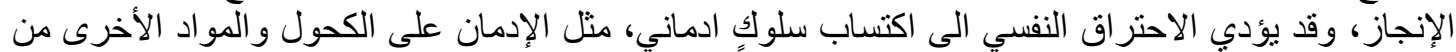




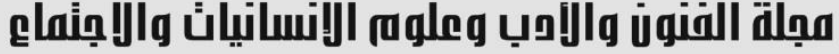

Journal of Arts, Literature, Humanities and Social Sciences www.jalhss.com

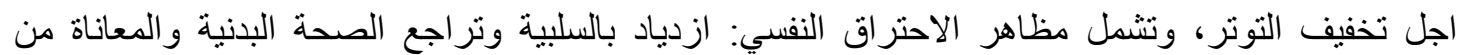

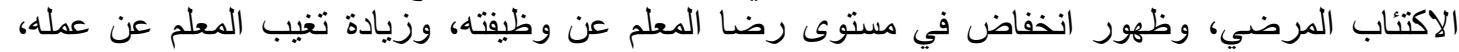

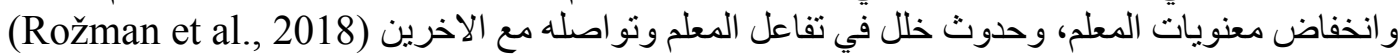

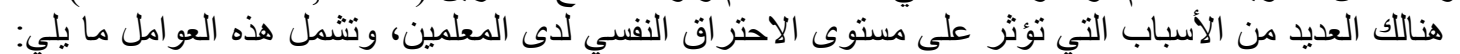

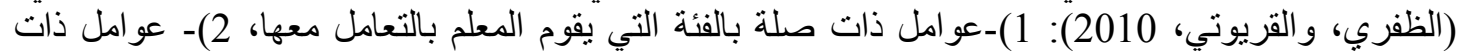

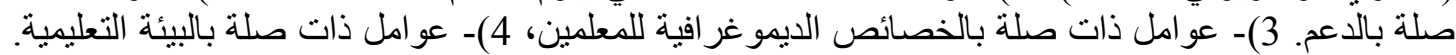

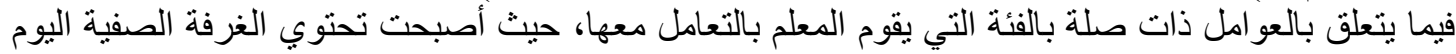

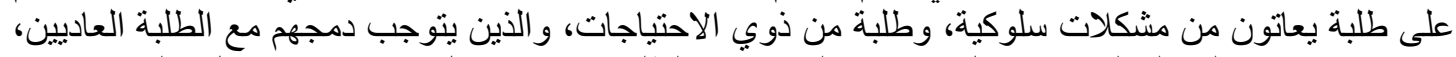

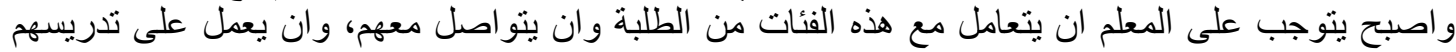

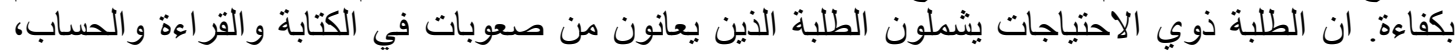

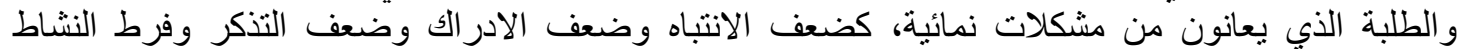

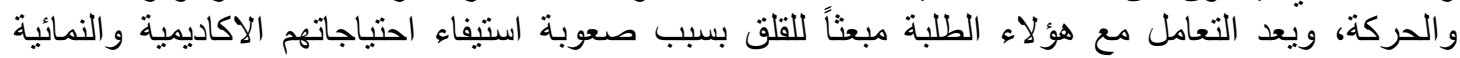

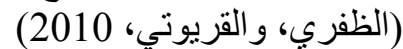

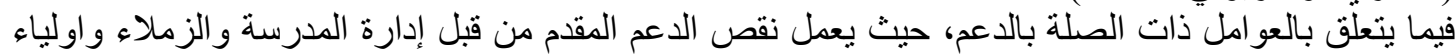

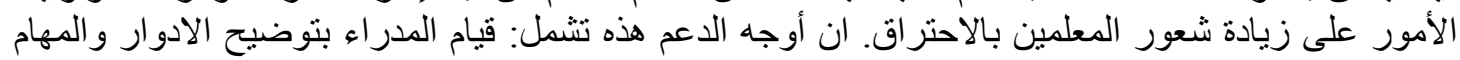

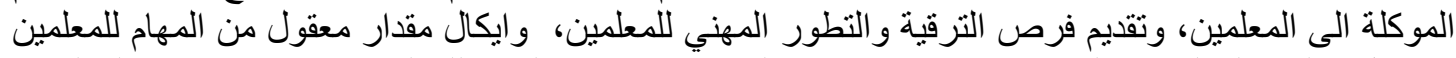
من قبل اولياء المعلمين والمدراء. يجدر الإنشارة الى ان النئ ان تقديم الدعم للمعلم سيسهم في تحفيز المعلمين،

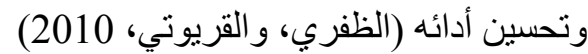

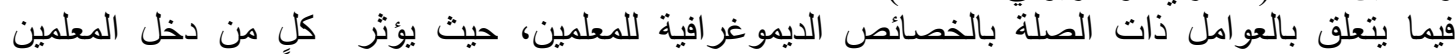

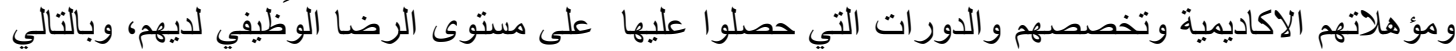

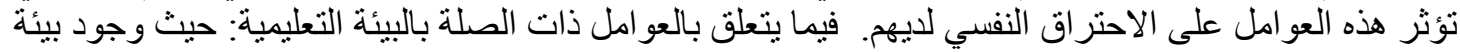

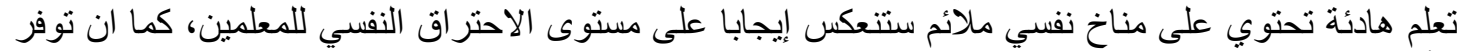

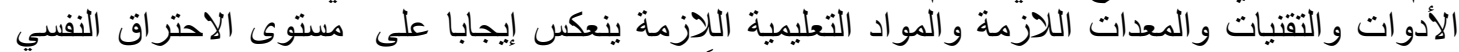

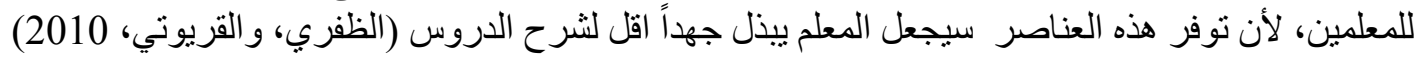

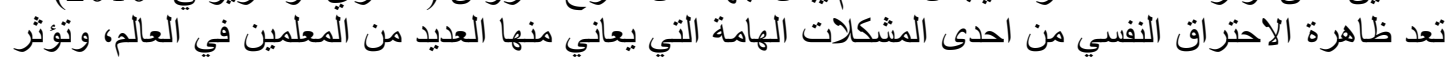

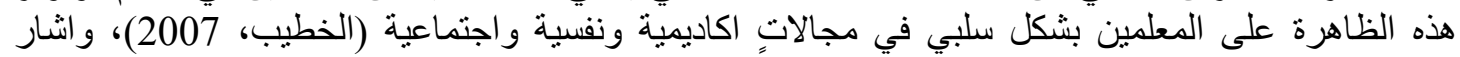

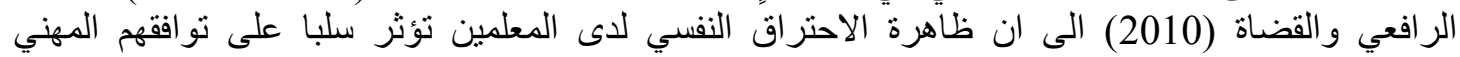

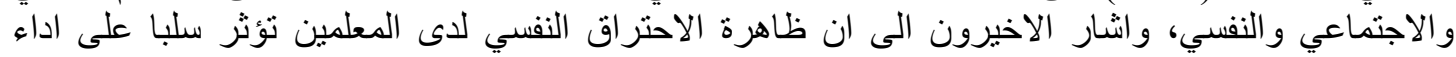

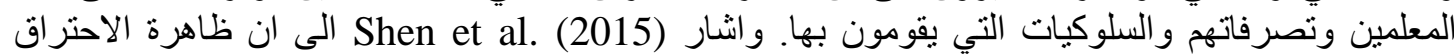

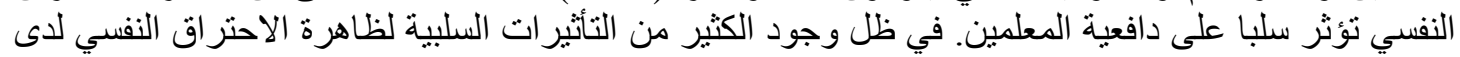

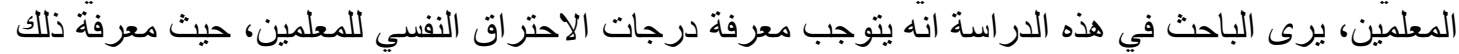

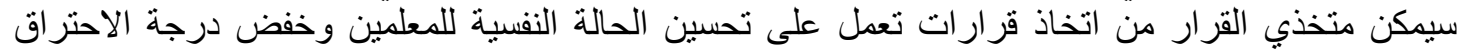

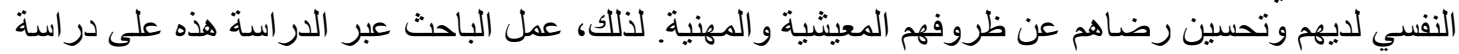

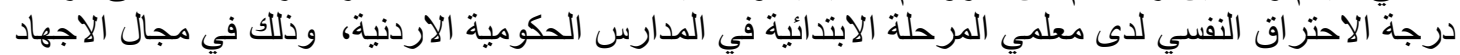

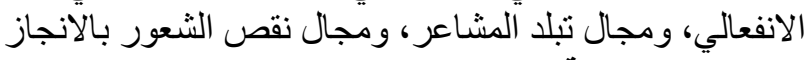

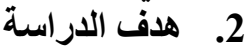

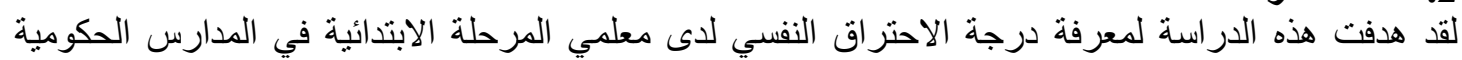

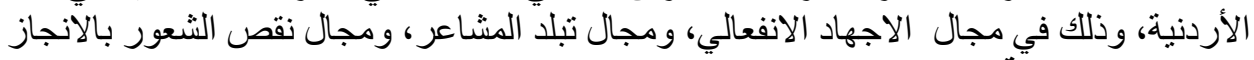

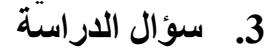
لقد هدفت هذه الدر اسة للإجابة على ما يلي:

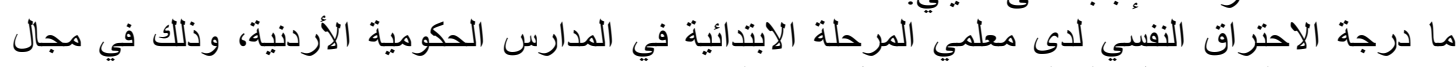
الاجهاد الانفعالي، ومجال تبلد المشاعر، ومجال نقص الثُعور بالانجاز؟ 


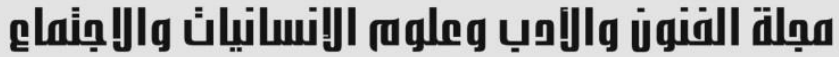

Journal of Arts, Literature, Humanities and Social Sciences www.jalhss.com

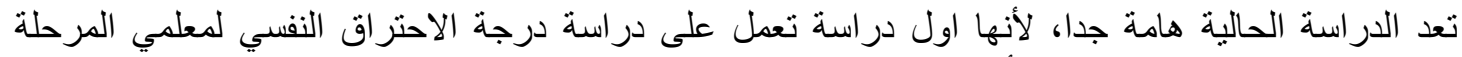

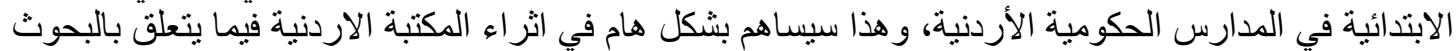

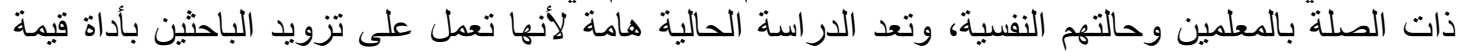

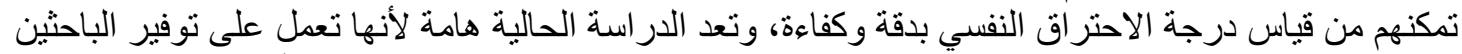

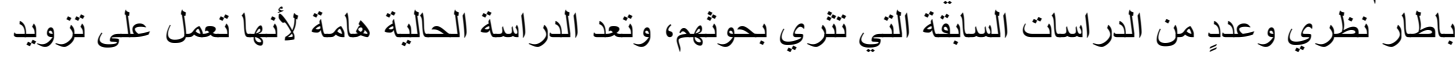

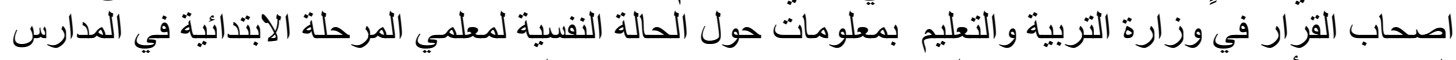

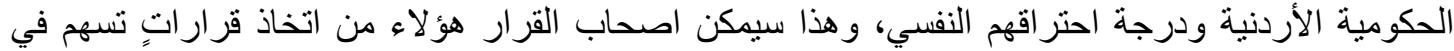

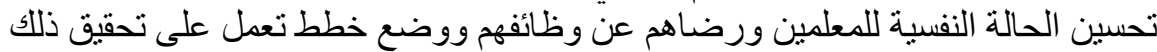
5

ـالحدود المكانية: تعمل الدر اسة الحالية على استهداف الصفوف الحف الإبتدائية في المدارس الحكومية الأردنية

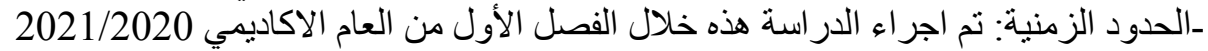

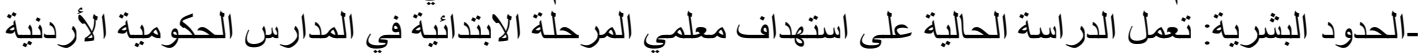

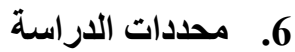
لا يمكن تعميم نتائج الدراسة هذهة، لأن النتائج تختلف من دراسة لأخرى باختلاف نوع الأداة، وعدد بنودها،

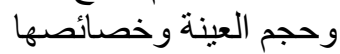
7. 7. تعريفات الاراسة

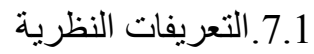

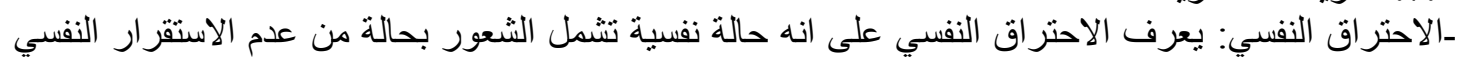

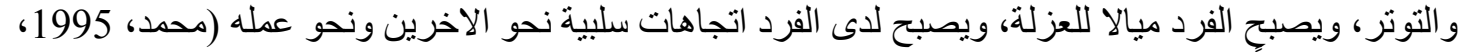

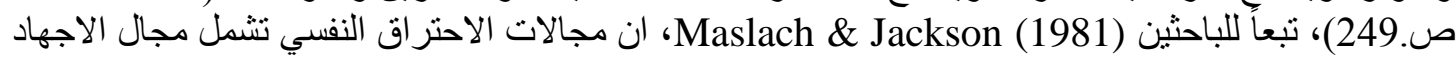

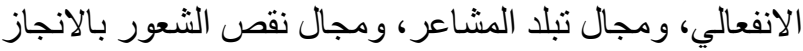

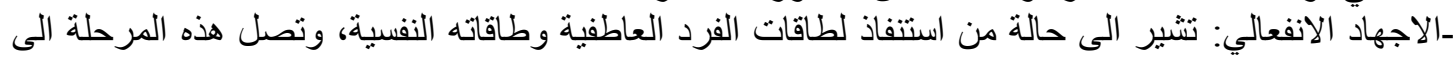

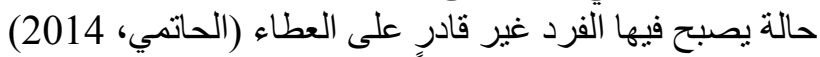

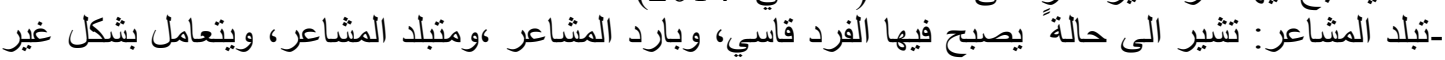

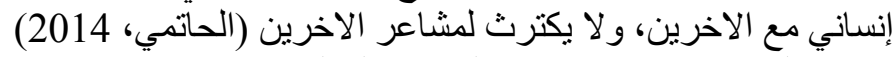

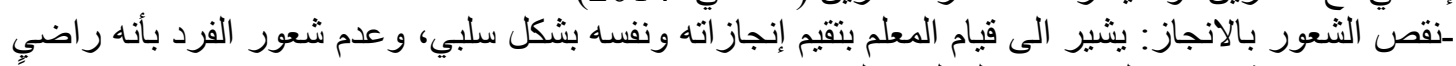

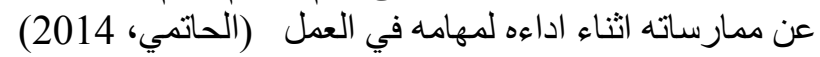
7.2 التعريفات التطبيقية التباه

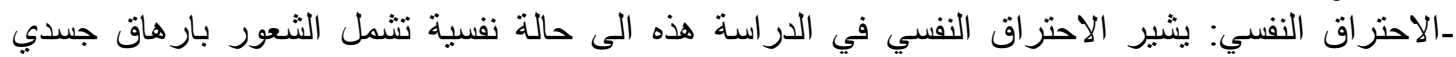

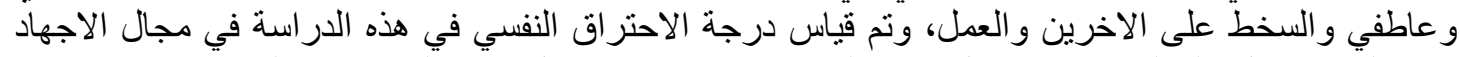

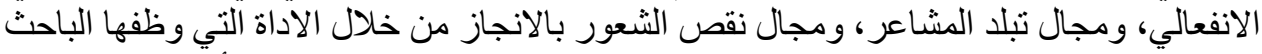

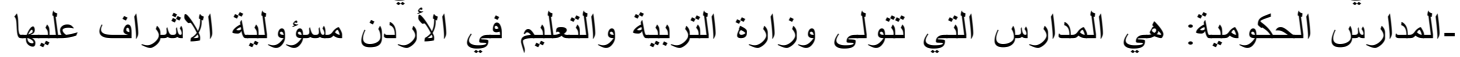
و ادارتها وتمو يلها النيا

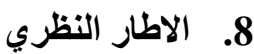

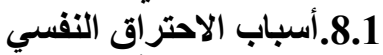

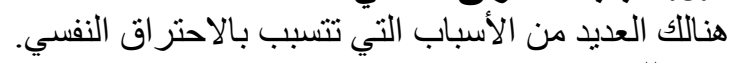

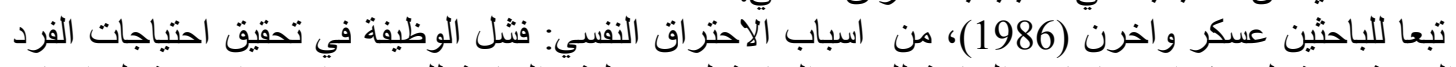

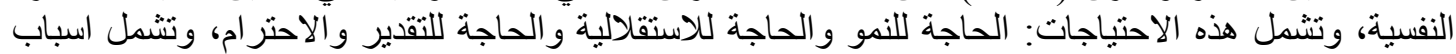

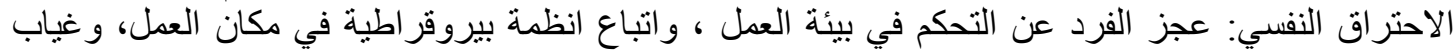

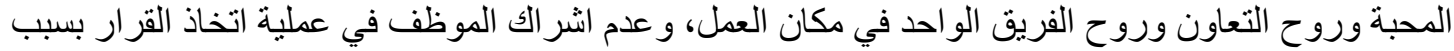

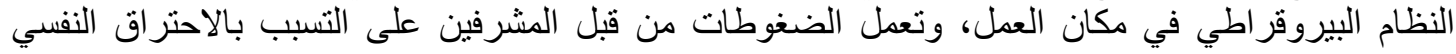




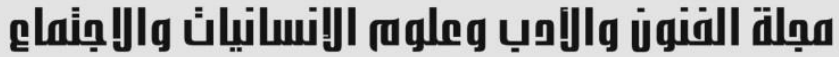

Journal of Arts, Literature, Humanities and Social Sciences www.jalhss.com

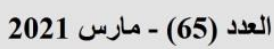

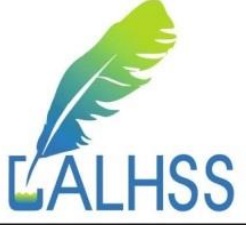

تبعا للباحث القماح (2002)، تتمثل اسباب الاحتراق النفسي بما يلي: ازدياد اعباء التنريس على المعلم، و عجز

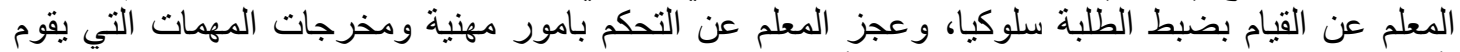

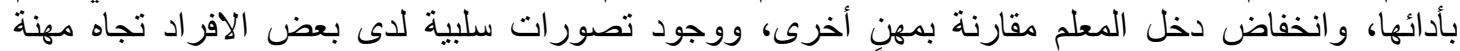
التدريس (القماح، 2002)

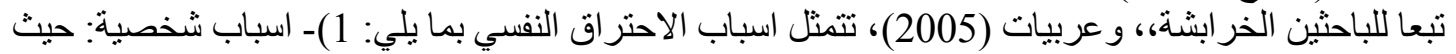

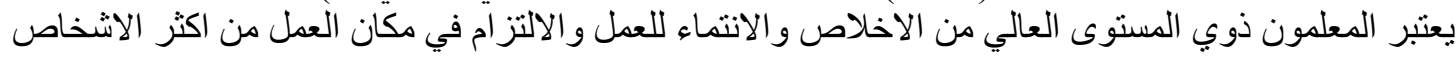

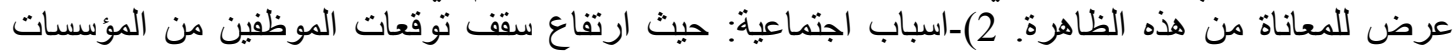

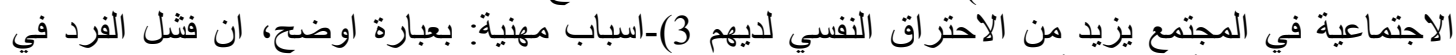

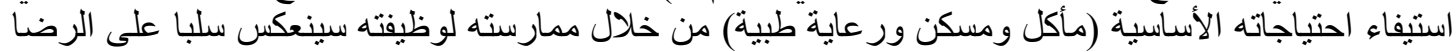

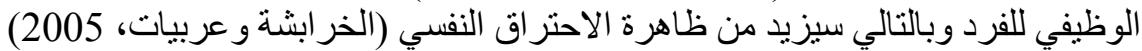

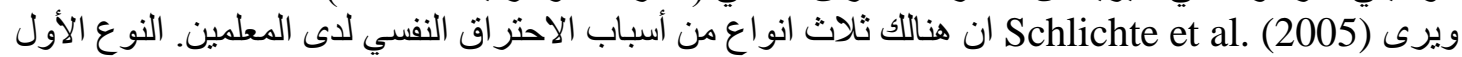

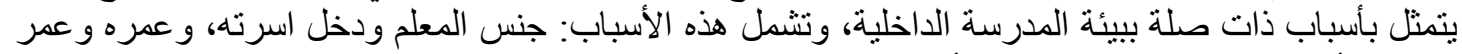

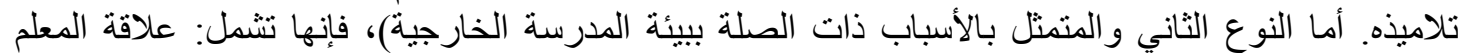

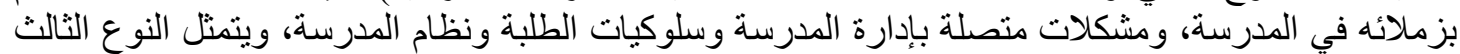

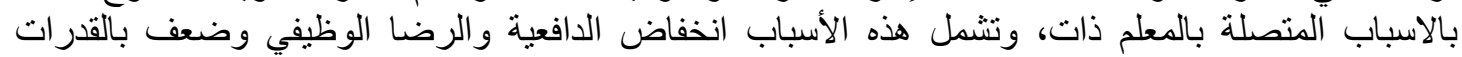

و المهار ات (Schlichte et al., 2005).

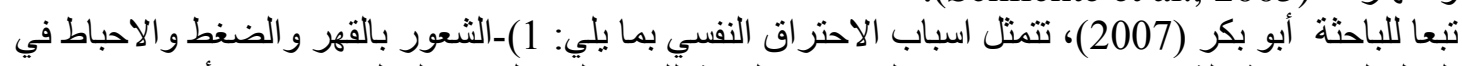

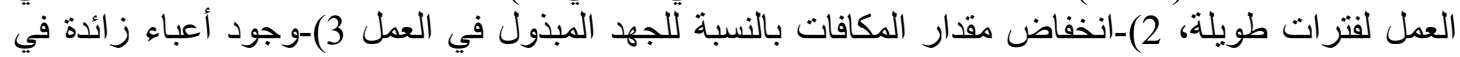

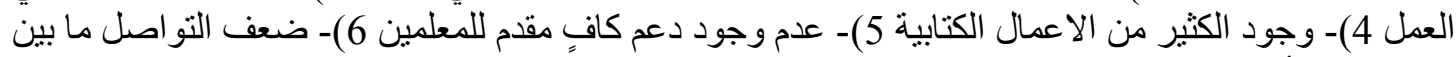

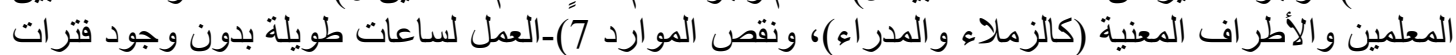

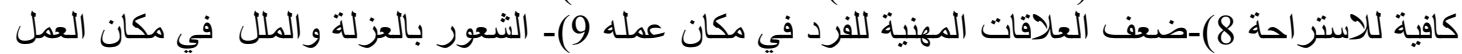

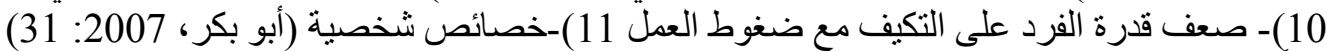

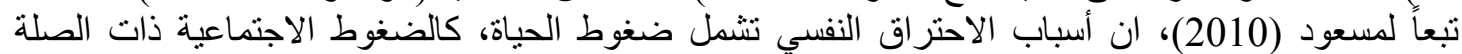

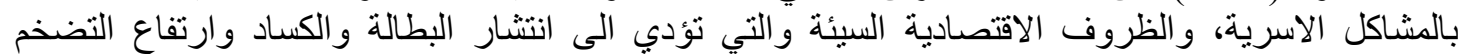

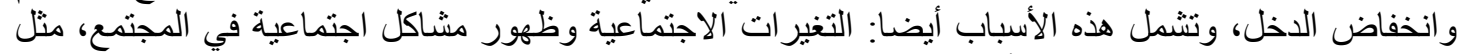

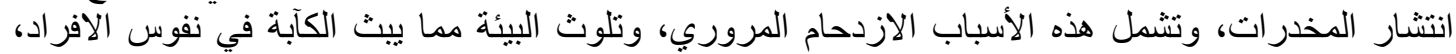

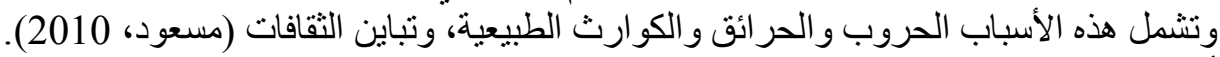

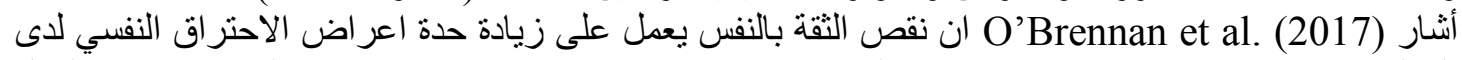

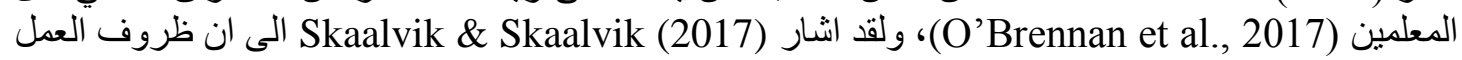

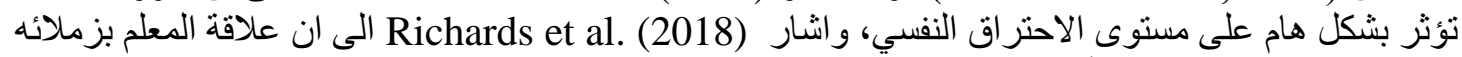

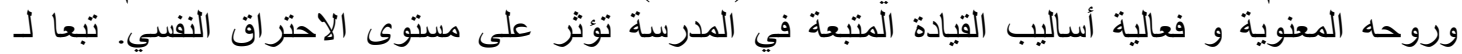

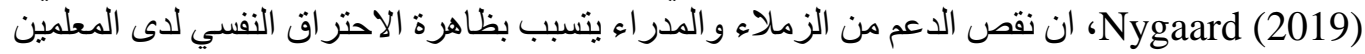

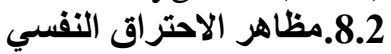

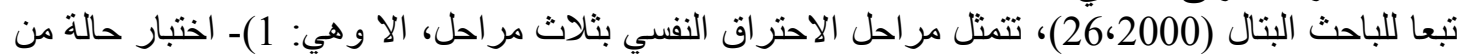

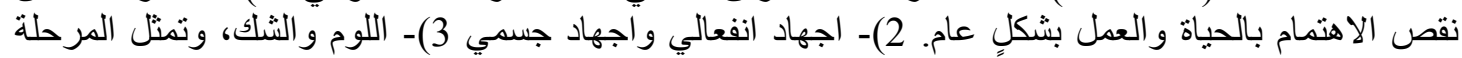

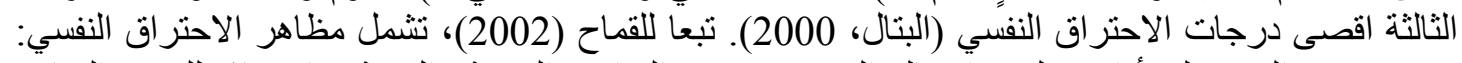

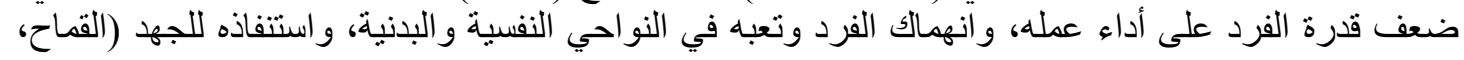

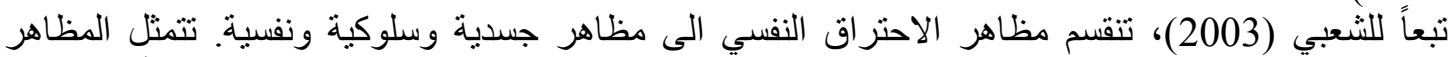

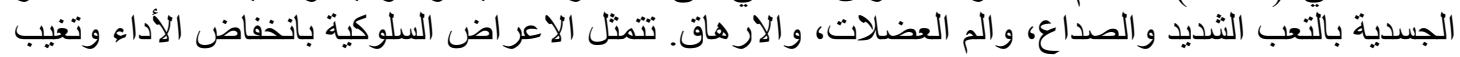

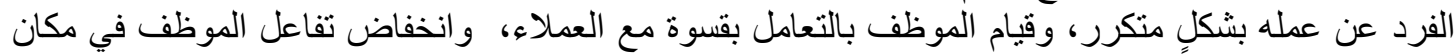

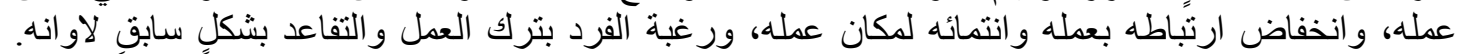

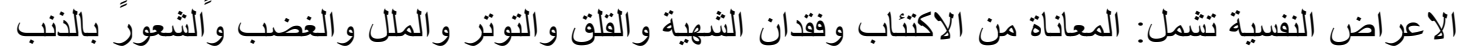

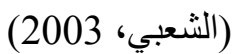




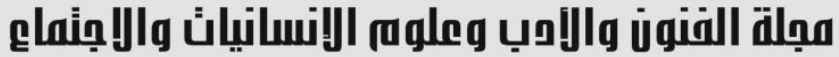

Journal of Arts, Literature, Humanities and Social Sciences www.jalhss.com

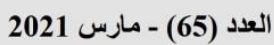

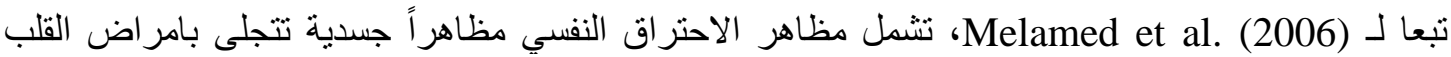

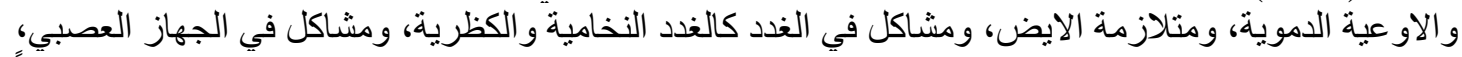

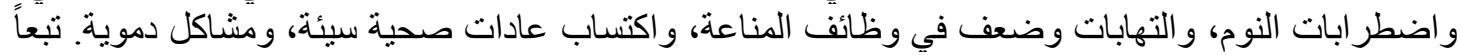

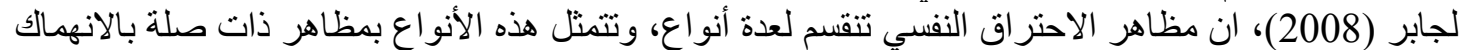

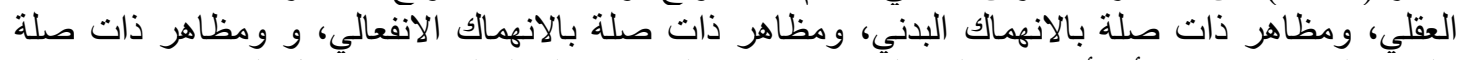

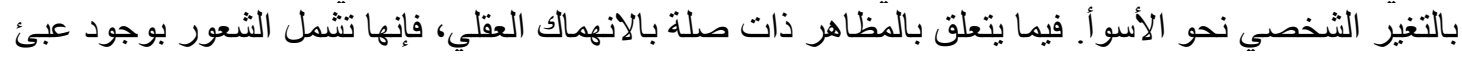

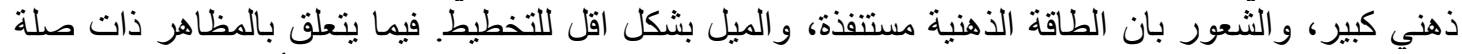

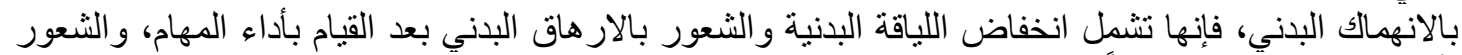

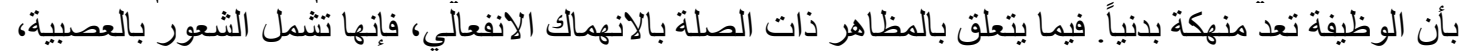

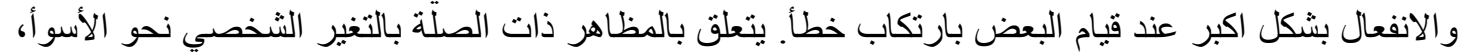

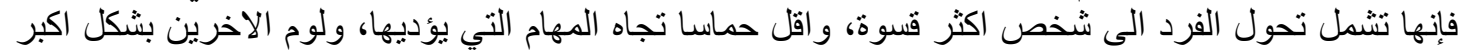

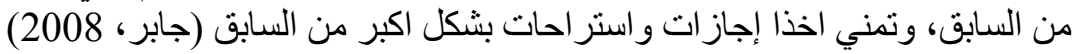

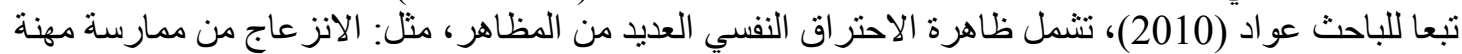

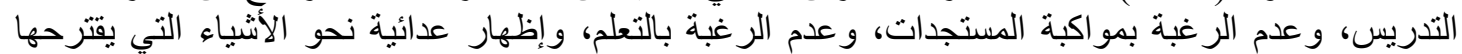

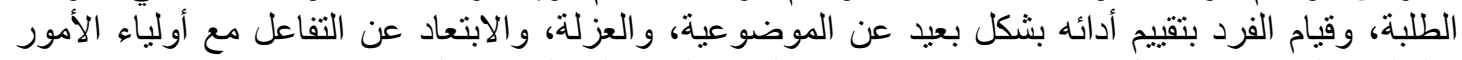

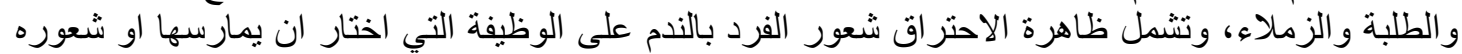

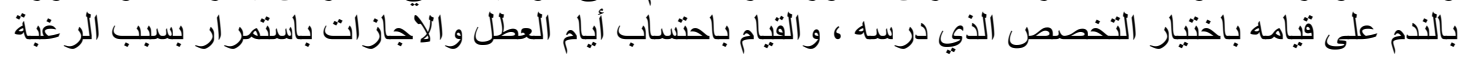

$$
\text { من التهرب من الوظيفة (عواد، بادئ 2010) }
$$

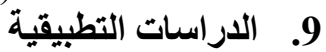

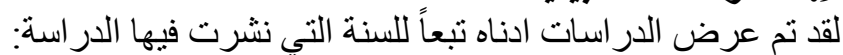

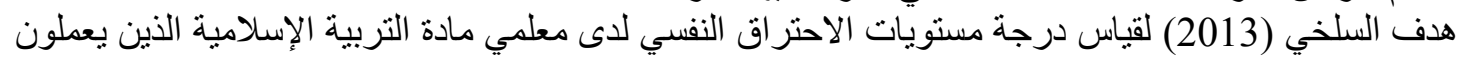

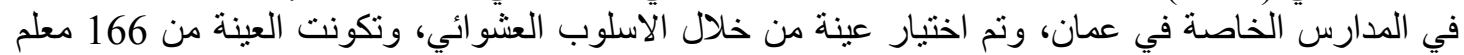

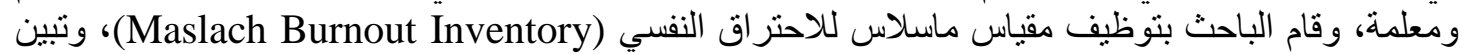

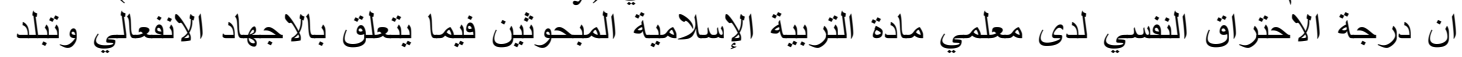

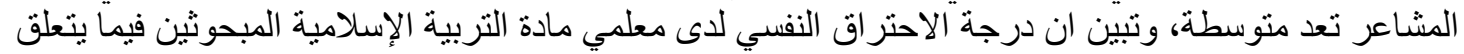

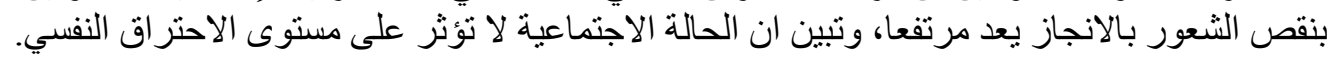

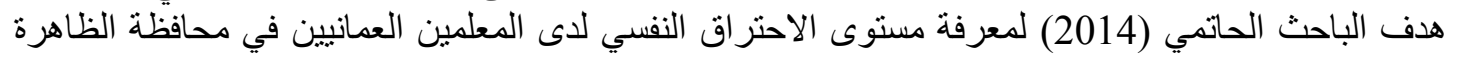

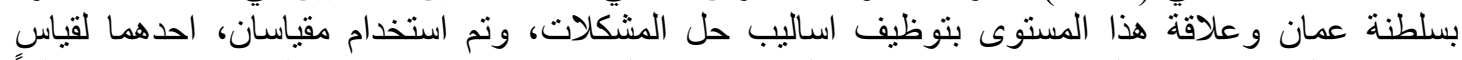

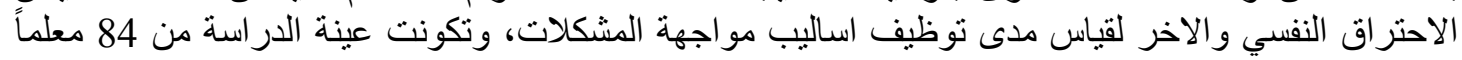

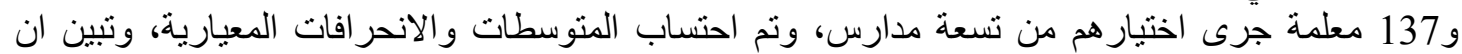

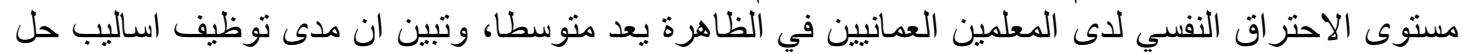

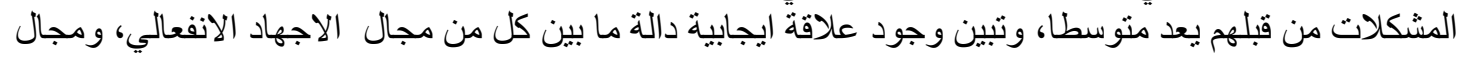

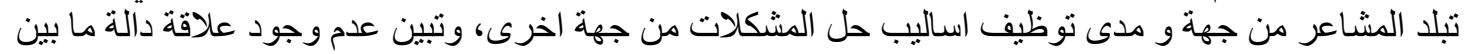

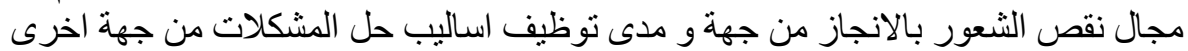

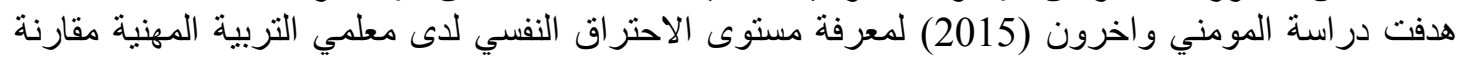

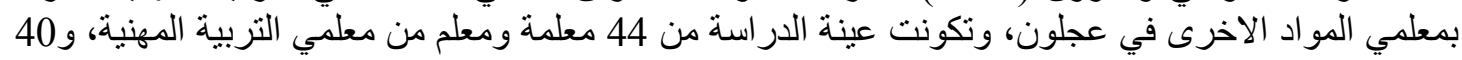

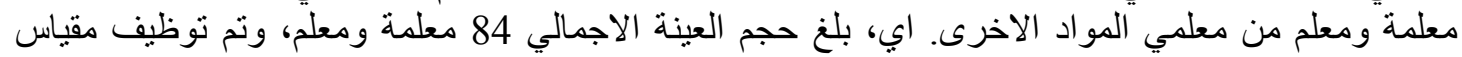

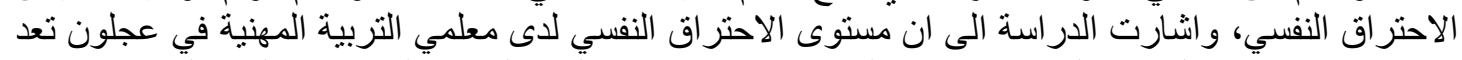

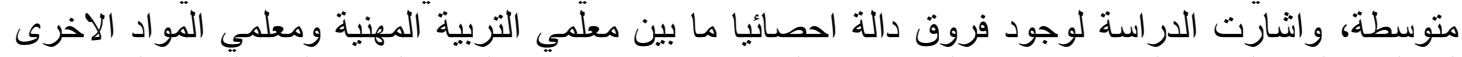

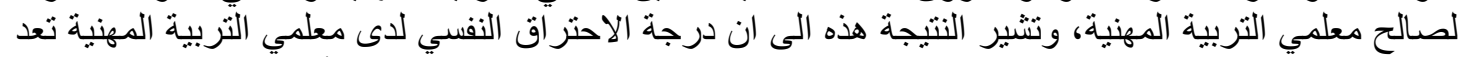

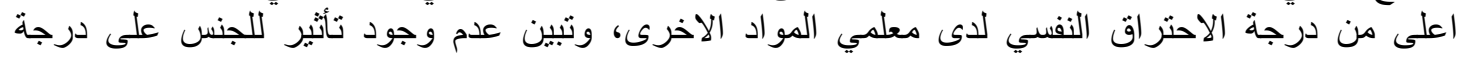
الاحتر اق النفسي للمبحوثين.

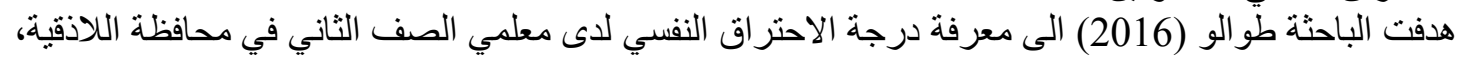
و عمل الباحث على اتباع نهج وصفي تحليلي، وتم توظيف استبيان، وتم اختيار عينة مكونة من لن 369 معلما، وتم 


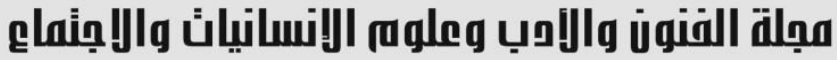

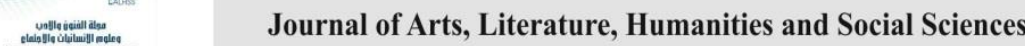
www.jalhss.com

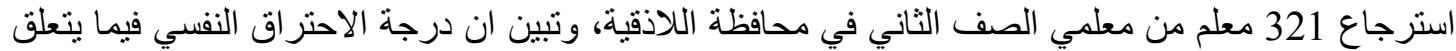

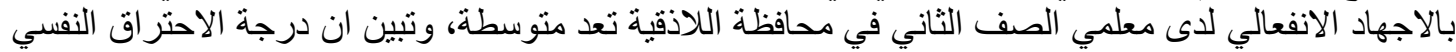

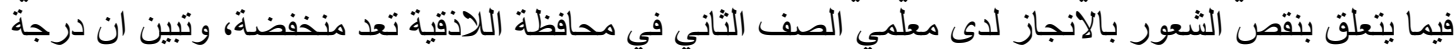

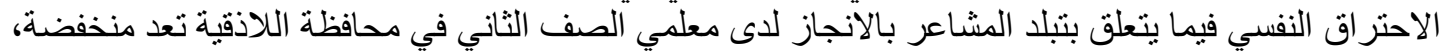

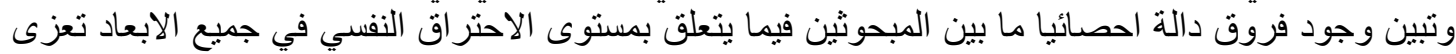

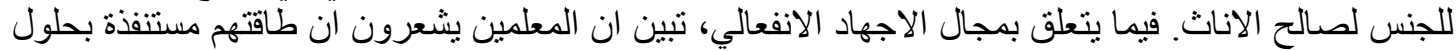

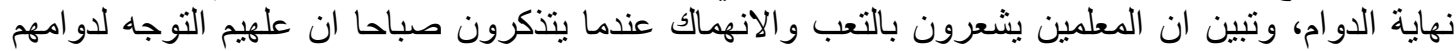

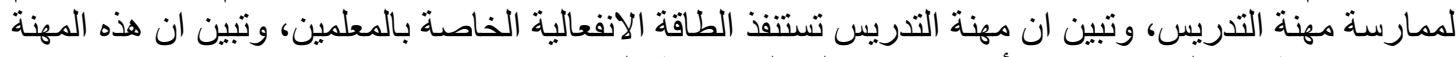

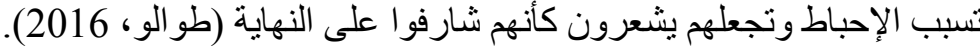

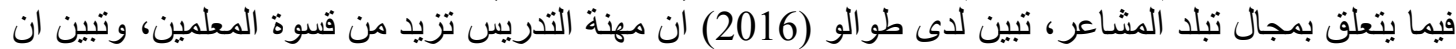

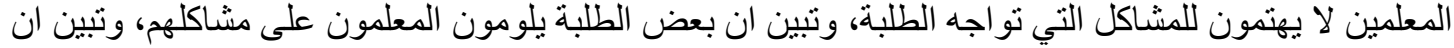

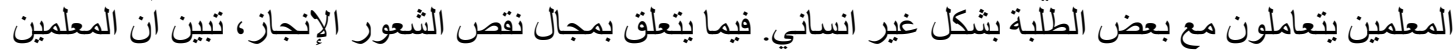

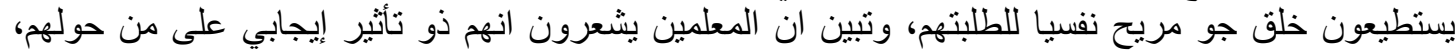

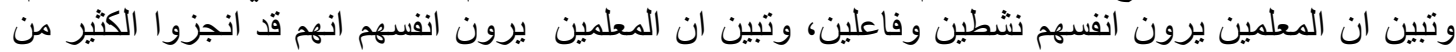

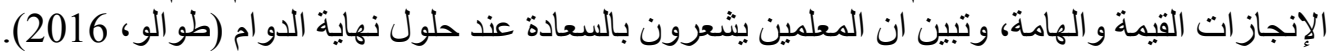

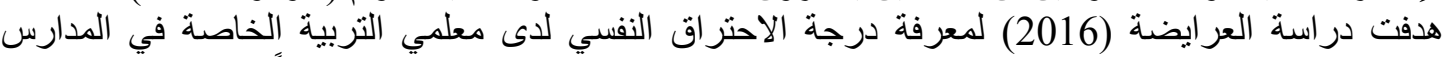

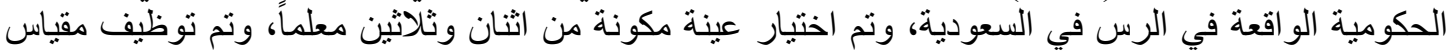

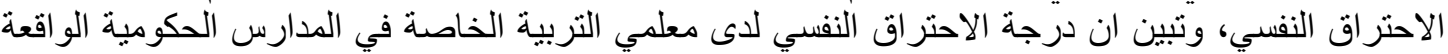

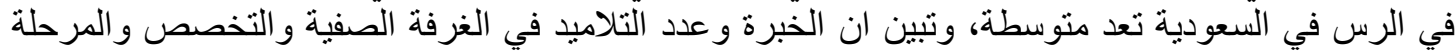

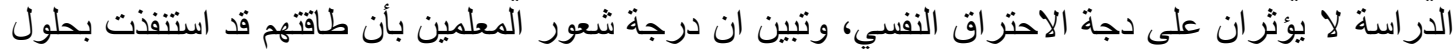

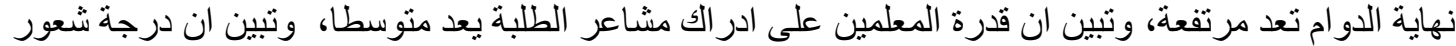

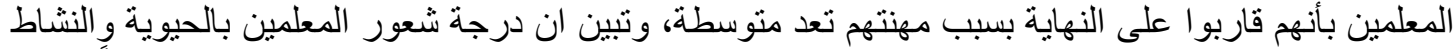

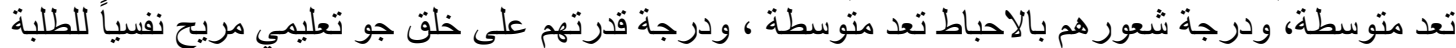

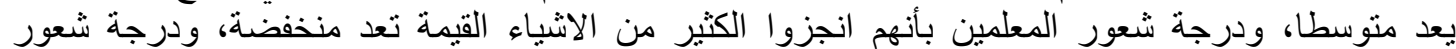
المعلمين بالانهماك صباحا عندما يتذكرون ان عليهم الذهاب للعمل تعد متوسطة.

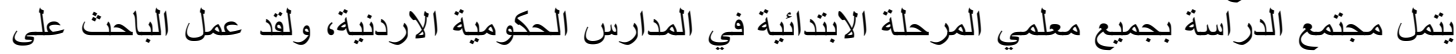

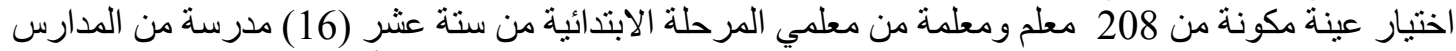

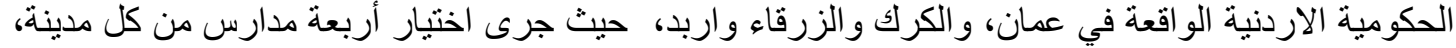

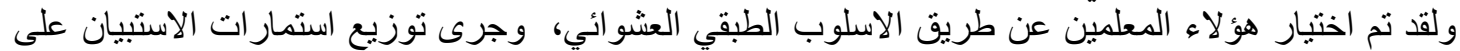

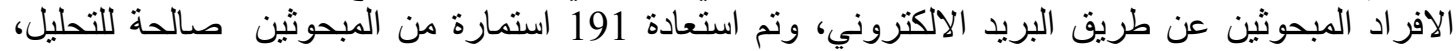

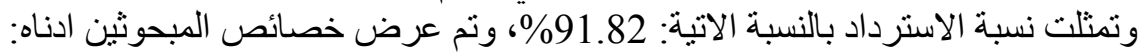

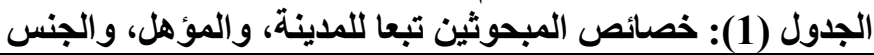

\begin{tabular}{|c|c|c|c|}
\hline النسبة & التكر ار ات & الفئة & المتغير \\
\hline 49.21 & 94 & ذكور & \multirow[t]{2}{*}{ الجنس } \\
\hline 50.78 & 97 & اناث & \\
\hline 25.13 & 48 & عمان & \multirow[t]{4}{*}{ المدينة } \\
\hline 25.65 & 49 & الكرك & \\
\hline 24.08 & 46 & الزرقاء & \\
\hline 25.13 & 48 & اربد & \\
\hline 74.869 & 143 & بكالوريو & المؤهل \\
\hline
\end{tabular}




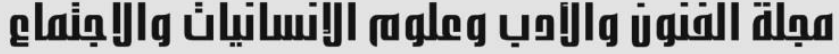

$\begin{gathered}\text { Journal of Arts, Literature, Humanities and Social Sciences } \\ \text { www.jalhss.com }\end{gathered}$
$=\quad$ Volume (65) - March 2021

\begin{tabular}{|c|c|c|}
\hline 14.13 & 27 & ماجستير \\
\hline 10.99 & 21 & دبلوم عالي \\
\hline 0 & 0 & دكتور اه \\
\hline
\end{tabular}

عدد افر اد المبحوثين: 191

10.3

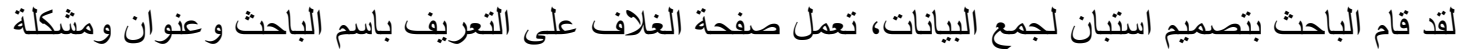

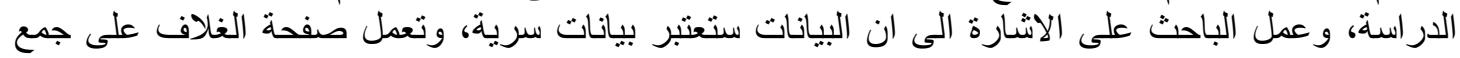

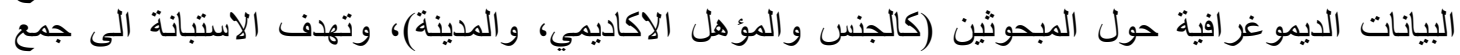

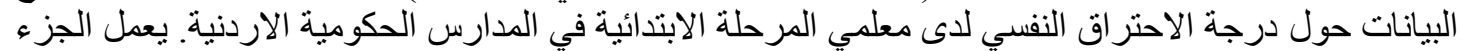

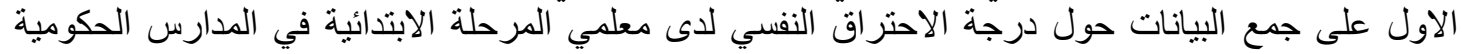

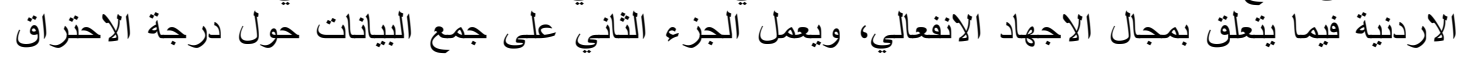

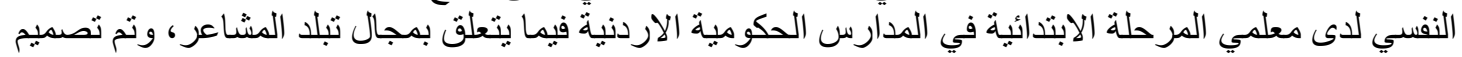

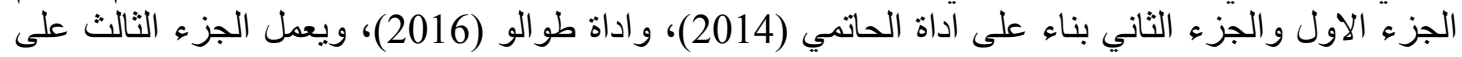

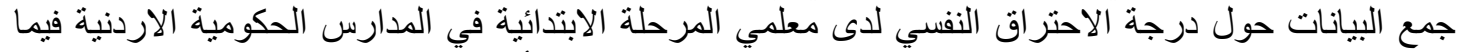

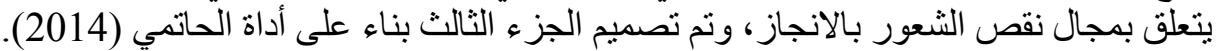

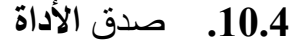

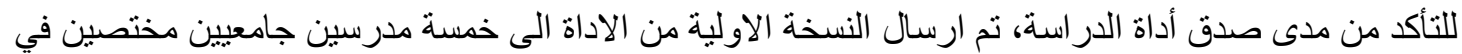

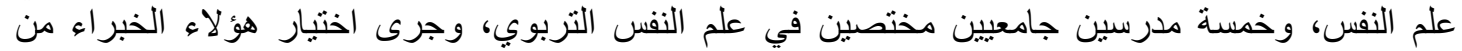

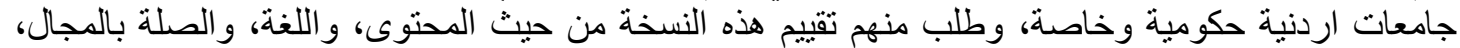

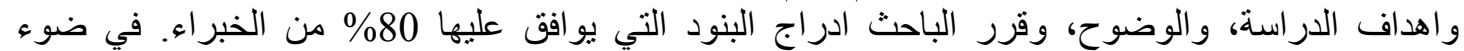

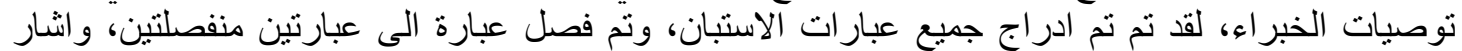

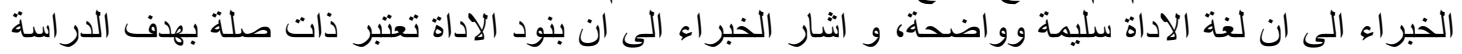
و المجال المعني الفي الخي

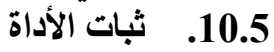
تم احتساب معامل كرونباخ الفا لكل مجال، وذللك لقياس ثبات الاستبانة الجدول (2): قيم معامل كرونباخ الفا لكل مجال من المجالات المستهدفة

\begin{tabular}{|c|c|c|}
\hline قيمة معامل كرونباخ الفا & 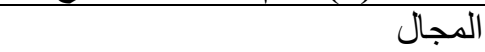 & الرقم \\
\hline 0.86 & المجال الأول: الاجهاد الانفعالي & .1 \\
\hline 0.79 & المجال الثناني: تبلد المشاعر & .2 \\
\hline 0.82 & المجال الثالث: نقص الثعور بالانجاز & .3 \\
\hline 0.82 & الإجمالي & \\
\hline
\end{tabular}

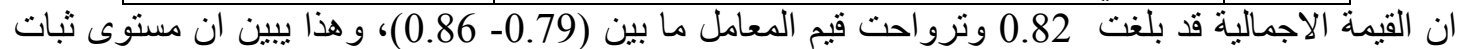

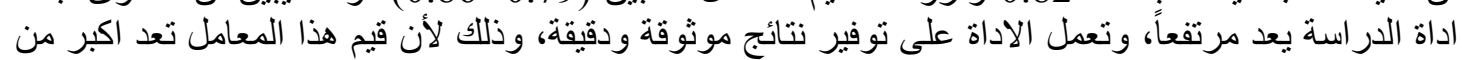

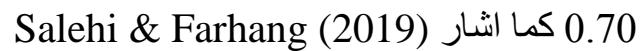
10.6. ادوات تحليل البيانات:

تم توظيف برنامج (SPSS) لتحليل الييانات ومعالجنها، وتم استخدام أساليب التحليل الوصفي (والمتمثلة

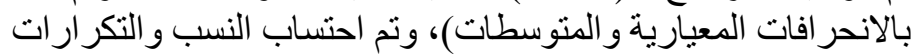
10.7 معايير التحليل من اجل تصنيف المتوسطات، تم اعتماد المعايير المذكورة ادناه، وتعد هذه المعايير معايير إحصائية 


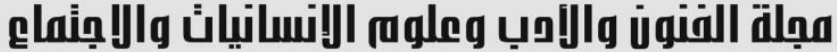

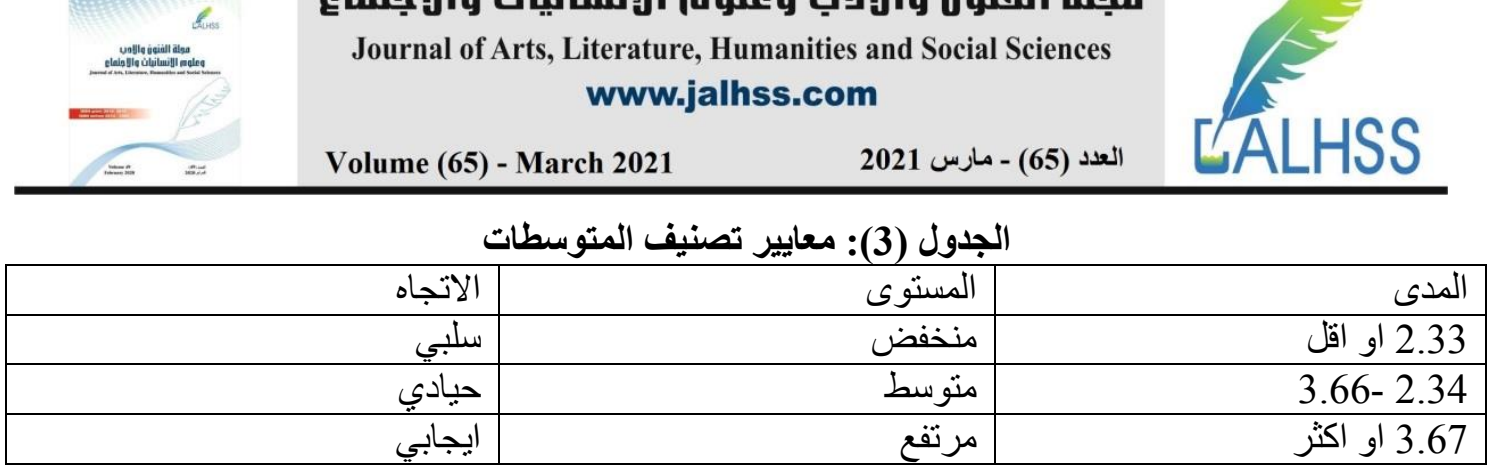

Aljbour (2020) : (المصدر (*

تم اعتماد مقياس ليكرت الخماسي المكون من الفئات و النقاط المدرجة ادناه الجدول (4): فئات ونقاط مقياس ليكرت الخماسي المكون من خمس فئات

\begin{tabular}{|c|c|}
\hline النقاط & 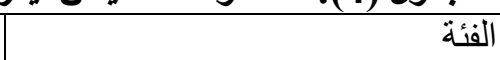 \\
\hline 5 & او افق بشدة \\
\hline 4 & أو افق \\
\hline 3 & حيادي \\
\hline 2 & لا أو افق \\
\hline 1 & لا لاو افق بشدة \\
\hline
\end{tabular}

Aljbour (2020): (المصدر)

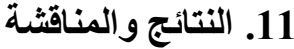

من اجل عرض إجابة هذا السؤال المدرج اعلاه، قام الباحث بحساب الانحر افات المعيارية والمتوسطات لكل

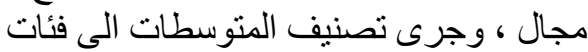

الجدول (5): المتوسطات والانحرافات المعيارية الخاصة بكل مجال من مجالات الدراسة

\begin{tabular}{|c|c|c|c|c|c|}
\hline المستوى & بة & الانحر افياري & الحسابي & 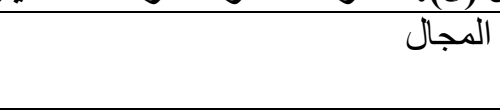 & الرق \\
\hline منخفض & 2 & 0.52 & 1.69 & المجال الأول: الاجهاد الانفعالي & .1 \\
\hline منخفض & 3 & 0.63 & 1.47 & المجال الثاني: تبلد المشاعر & .2 \\
\hline منخفض & 1 & 0.40 & 1.75 & المجال الثالث: نقص الثعور بالانجاز & .3 \\
\hline منخفض & & 0.51 & 1.68 & 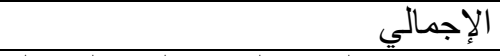 & \\
\hline
\end{tabular}

لقد تبين ان درجة الاحتراق النفسي لدى معلمي المرحلة الابتدائية في المدارس الحكومية الاردنية تعد منخفضة الإنية

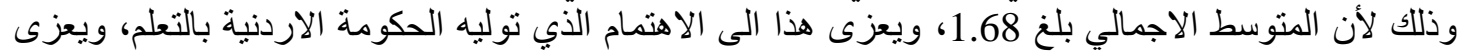

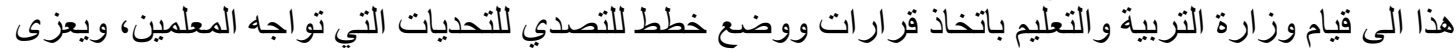

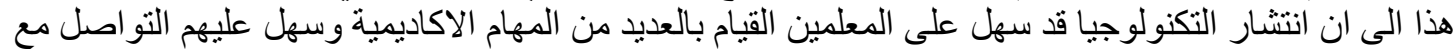

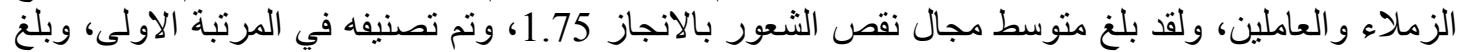
متوسط الاجهاد الانفعالي 1.69، وتم تصنيفه في المرتبة الثانية، وبلغ متوسط مجال تبلد المشاعر 1.47، وتنم تصنيفة في المرتبة الثالثة ـ المجال الأول: الاجهاد الانفعالي 


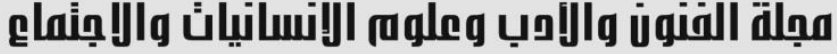

Journal of Arts, Literature, Humanities and Social Sciences www.jalhss.com

Volume (65) - March 2021

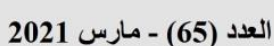

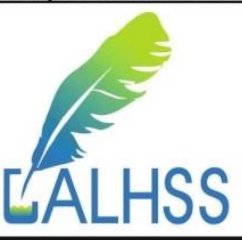

الجدول (6): درجة الاحتراق النفسي لاى معلمي المرحلة الابتدائية في المدارس الحكومية الاردنية فيما يتعلق بمجال (الاجهاد الانفعالي)

\begin{tabular}{|c|c|c|c|c|}
\hline 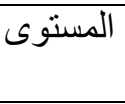 & 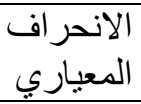 & الحسابي الحتوسي & 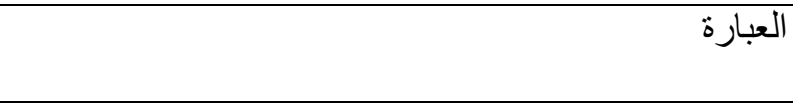 & 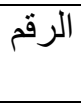 \\
\hline منخفض & 0.52 & 1.85 & اشعر ان عملي يستنفذ طاقاتي من الناحية الانفعالية و النفسية & 1 \\
\hline منخفض & 0.14 & 2.31 & اشعر ان عملي بستنفذ طاقاتي من الناحية الجسدية & .2 \\
\hline منخفض & 0.83 & 1.96 & لعملي لممارسة مهنة التدريس استيظ صباحا و اتذكر ان علي الذهاب & 3 \\
\hline منخفض & 0.55 & 1.37 & بالاجهاد التعامل مع الناس في العمل خلال اليوم يسبب لي الثعور & .4 \\
\hline 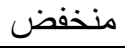 & 0.69 & 1.27 & اشعر بالإحباط بسبب ممارسة مهنة التدريس & .5 \\
\hline 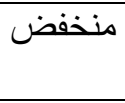 & 0.88 & 1.81 & التندريسر وكأنني شارفت على النهاية نتيجة ممارسة مهنة & 6 \\
\hline منخفض & 0.29 & 1.59 & ينتابني صداع اثناء عملي بسبب ممارستي لهذه المهنة & .7 \\
\hline منخفض & 0.46 & 1.48 & المهنتيني شعور بالغثيان اثثاء عملي بسبب ممارستي لهذه & .8 \\
\hline منخفض & 0.39 & 1.62 & اشعر بالاختنتاق اثناء ممارستي لمهنة التدريس & .9 \\
\hline منخفض & 0.52 & 1.69 & الإجمالي & \\
\hline
\end{tabular}

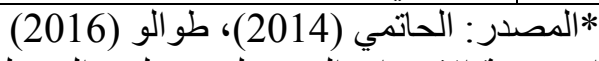

تبين ان درجة الاحتراق النفسي لدى معلمي المرحلة الابتدائية في الددارس الحكومية الاردنبة فيما يتعلق بمجال

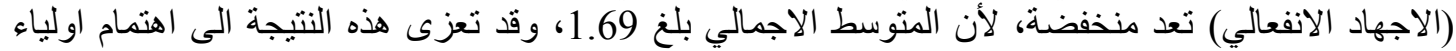

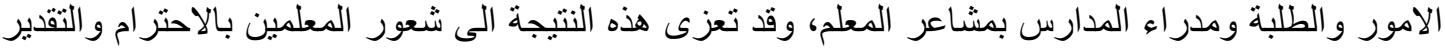

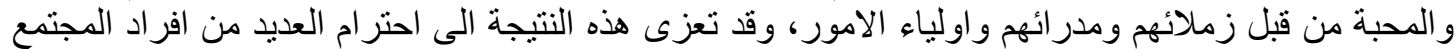

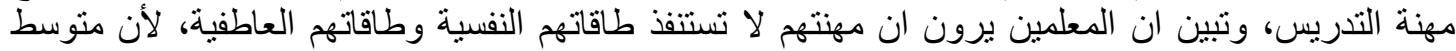

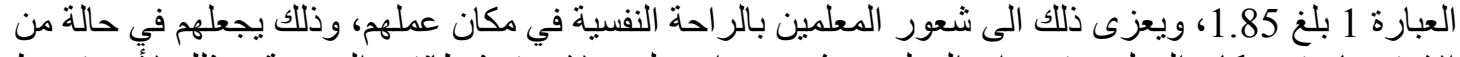

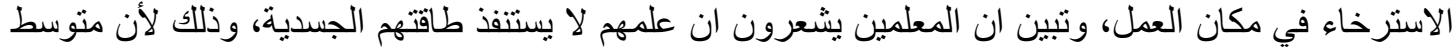

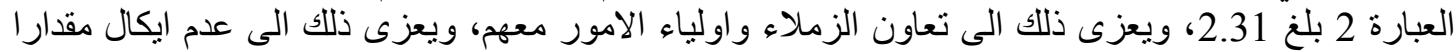

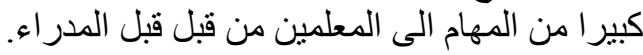

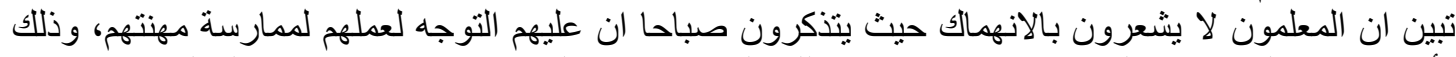

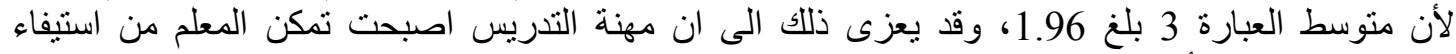

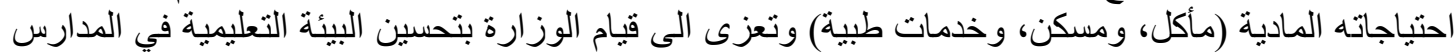

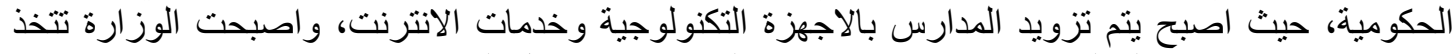

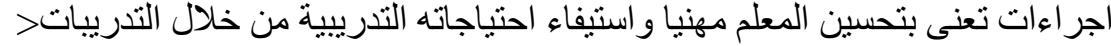

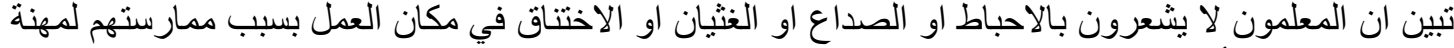

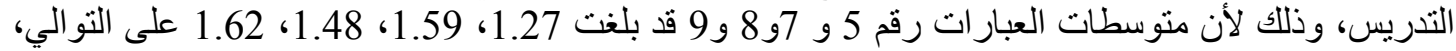

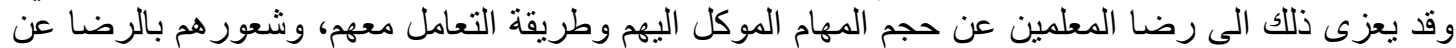

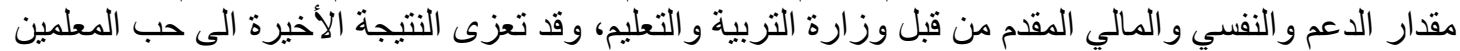

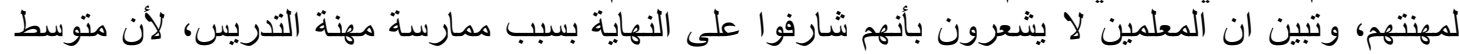

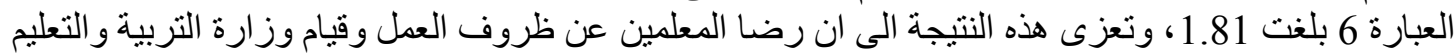
بتحسين أوضاعهم المالية ينعكس إيجابا على شعور هم بالامل وحبهم للحياه 


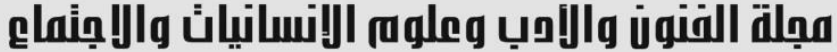

Journal of Arts, Literature, Humanities and Social Sciences www.jalhss.com

الجدول (7): درجة الاحتراق النفسي لدى معلمي المرحلة الابتدائية في المدارس الحكومية الاردنية فيما يتعلق

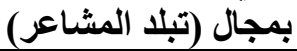

\begin{tabular}{|c|c|c|c|c|}
\hline المستوى & الانحر افياري & الحسابي & 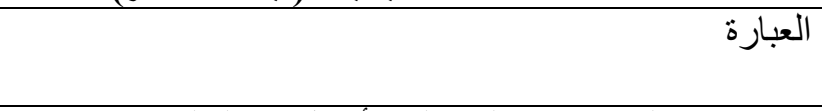 & 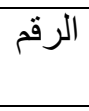 \\
\hline منخفض & 0.62 & 2.25 & الا انتعر ان لدي رغبة بالبقاء لمدة أطول مع الطلبة عند قضائي & .1 \\
\hline 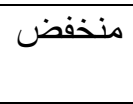 & 0.80 & 2.17 & الا ارغة التي في خوض فيها الاحاديث مع الأشخاص الموجودين في & .2 \\
\hline 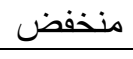 & 0.91 & 1.05 & لقد أصبحت قاسي القلب بسبب ممارستي لمهنة التدريس & .3 \\
\hline 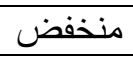 & 0.25 & 1.18 & لا اشعر بالسعادة عند قيامي بمناقنشة الطلبة بخصوص مشاكلهم & .4 \\
\hline منخفض & 0.47 & 0.52 & لا اعامل الطلبة بشكل انساني أحيانا & .5 \\
\hline منخفض & 0.86 & 1.13 & ألتبريس اتعامل بقسوة مع عائلتي بسبب ممارستي لمهنة & .6 \\
\hline 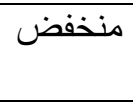 & 0.74 & 1.66 & عند التعامل مع الاخرين لمهنة التدريس قد جعلنتي منبلد المشاعر وقاسيا & .7 \\
\hline منخفض & 43 & 1.38 & يلقي طلبني اللوم علي بسبب مشاكلهم & .8 \\
\hline 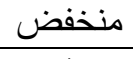 & 0.59 & 1.92 & ان المشاكل التي تو اجه طلبتي لا تهمني & .9 \\
\hline 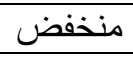 & 0.63 & 1.47 & اجمالي & \\
\hline
\end{tabular}

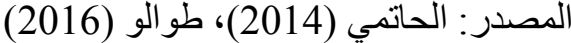

تبين ان درجة الاحتر اق النفسي لدى معلمي المرحلة الابتدائية في المدارس الحكومية الاردنية فيما يتعلق بمجال

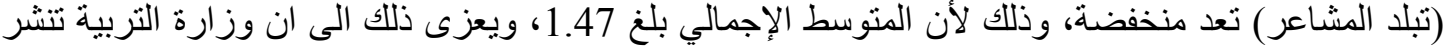

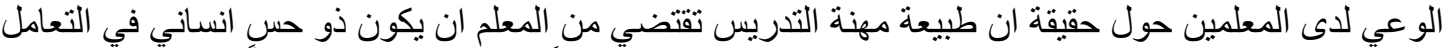

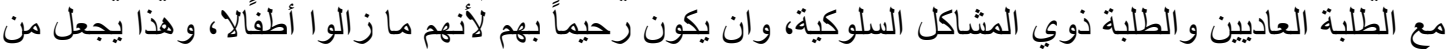

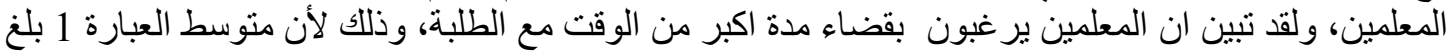

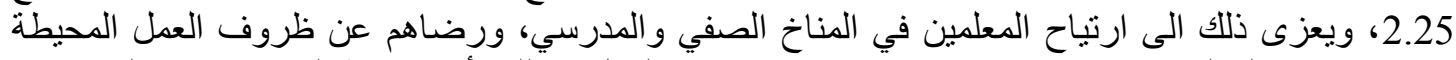

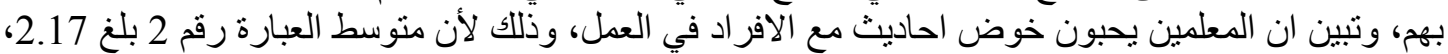

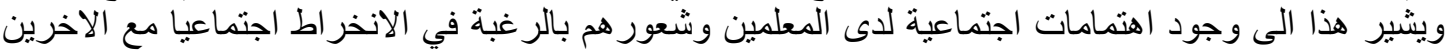
و والرغبة بتكوين صداقات اجتماعية.

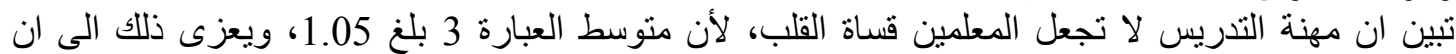

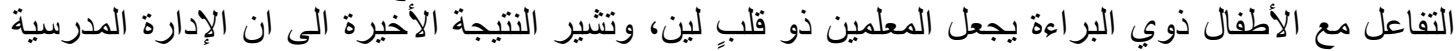

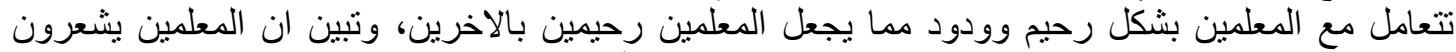

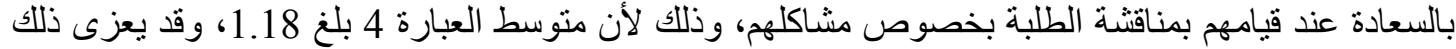

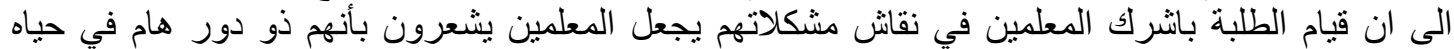

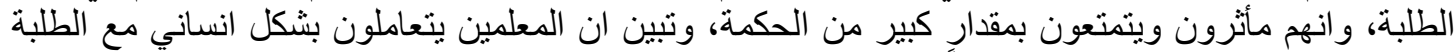

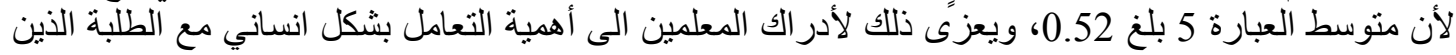

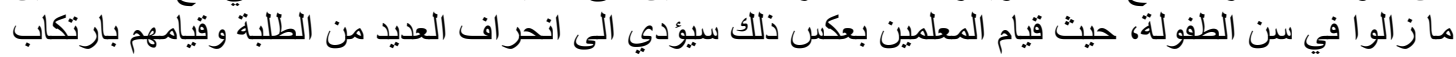

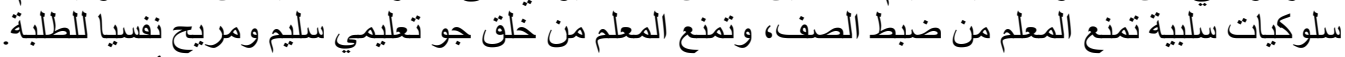

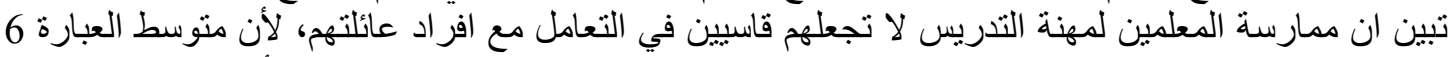

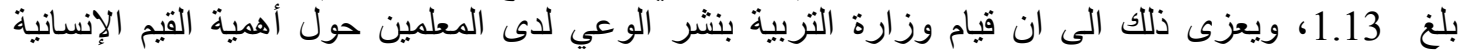

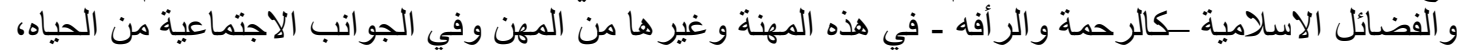

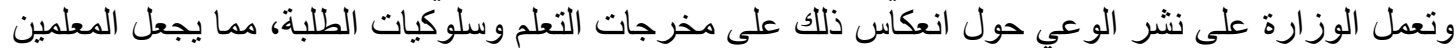

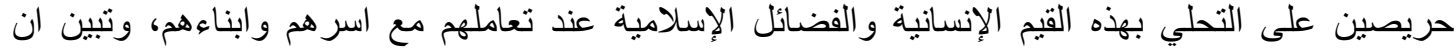




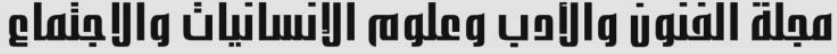

Journal of Arts, Literature, Humanities and Social Sciences www.jalhss.com

المشكلات التي تواجه الطلبة تهم المعلمين، وذللك لأن متوسط العبارة 9 بلغ 1.92، ويعزى ذلك الى ادرالك

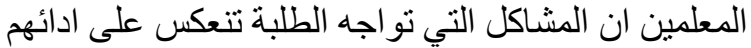

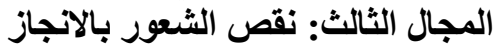

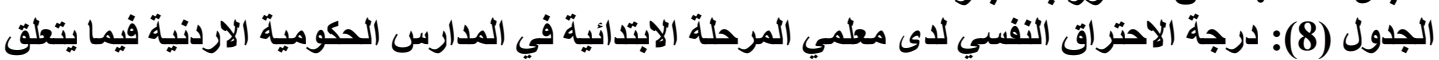
بمجال (نقص الثعور بالانجاز)

\begin{tabular}{|c|c|c|c|c|}
\hline المستوى & المعياري & الحسابي & 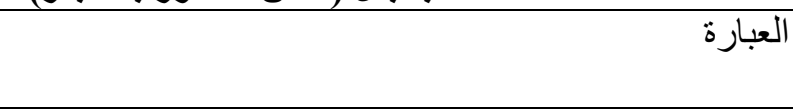 & 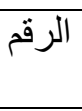 \\
\hline منخفض & 0.24 & 1.68 & لا اشعر اني نشط وفعال & .1 \\
\hline منخفض & 0.35 & 1.90 & لم التدريس الكثبر من الأشياء القيمة اثناء ممارستي لمهنة & .2 \\
\hline منخفض & 0.20 & 1.83 & ولا اقوم بمعالجة المشكلات التي تولى اجه طلبتي بشكلٍ ذو فعالية & .3 \\
\hline منخفض & 0.19 & 1.14 & لاعلون اشعر ان فنالك الثر إيجابي لي على الأشخاص الذين & .4 \\
\hline منخفض & 0.48 & 2.23 & لا أقومة بمعالجة المشكلات الانفعالية التي تحدث داخل & .5 \\
\hline منخفض & 0.67 & 1.70 & لا استطيع ان اهيئ جو ا من الهذو ء والر احة لطلبتي & .6 \\
\hline منخفض & 0.72 & 1.82 & لا استطيع فهم مشاعر طلبتي & .7 \\
\hline منخقض & 0.40 & 1.75 & اجمالي & \\
\hline
\end{tabular}

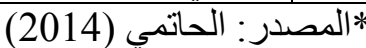

تبين ان درجة الاحتراق النفسي لدى معلمي المرحلة الابتدائية في المدارس الحكومية الاردنية فيما يتعلق بمجال

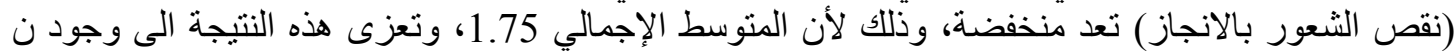

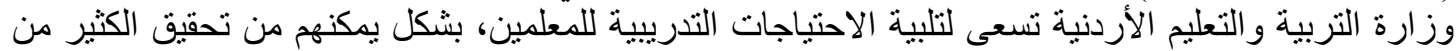

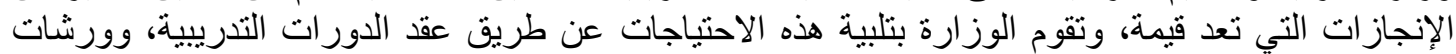

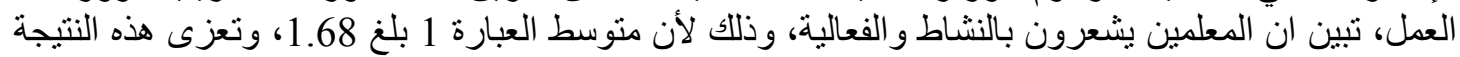

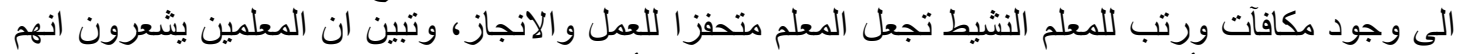

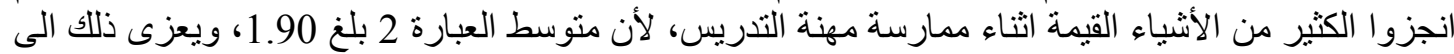
ان التكنولوجيا قد مكنت المعلمين من الاطلاع على تجارب عالمية، وهذا مكنهم من انجاز الكثير من المهام

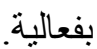

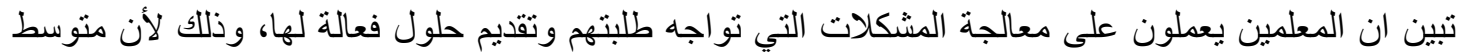

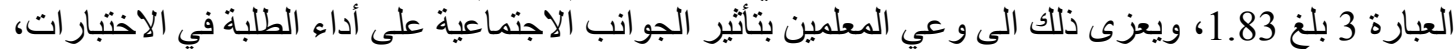

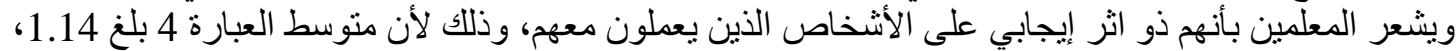

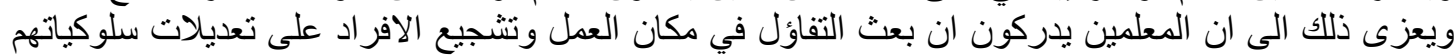

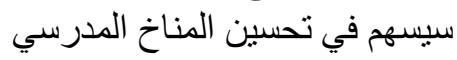

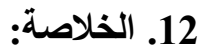
وتبين ان درجة الاحتر اق النفسي لدى معلمي المرحلة الابتدائية في المدارس الحكومية الأردنية تعد منخفضة في

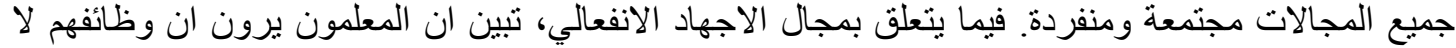

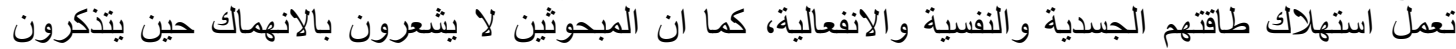

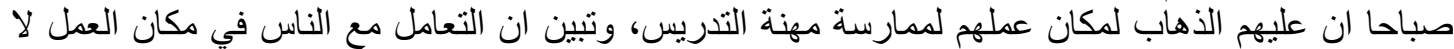

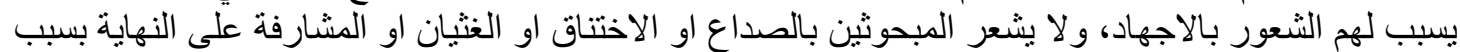




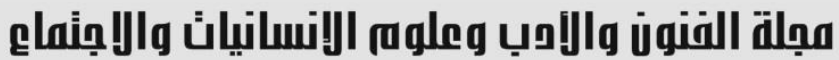

Journal of Arts, Literature, Humanities and Social Sciences www.jalhss.com

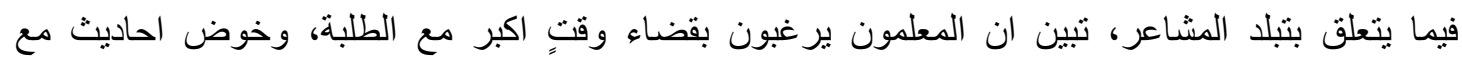

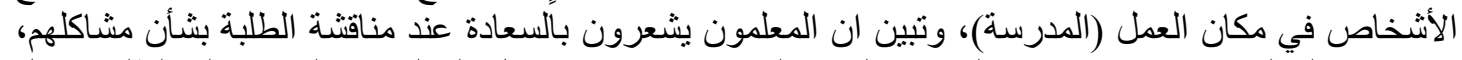

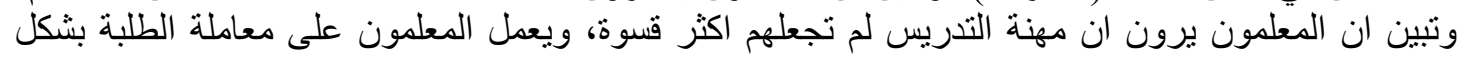

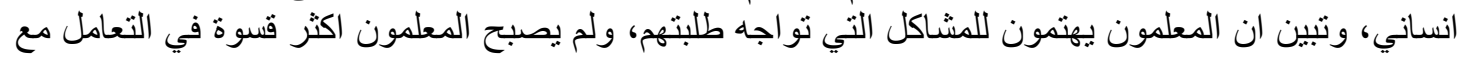
افر اد عائلتهم. فيما يتعلق بنقص الشعور الإنجاز، تبين ان المعلمين بشعرون بالنشاط والفعالية ويشعرون انهم انجزوا الكثير

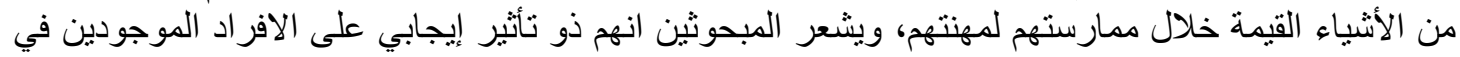

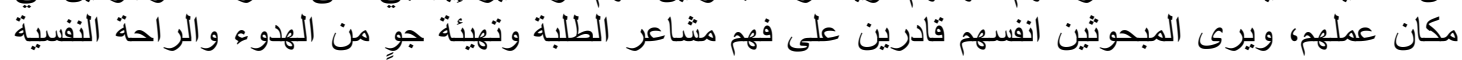

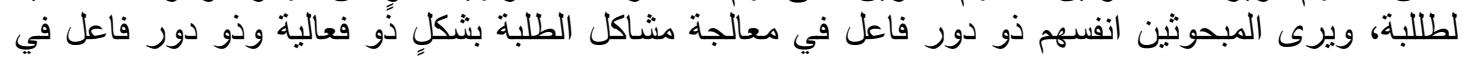
معالجة المشاعل الانفعالية التي تحدث أفئ داخل المدرسة.

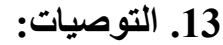
يوصي الباحث بما يلي:

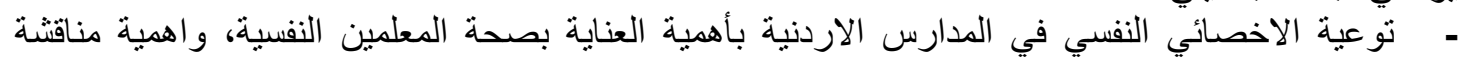

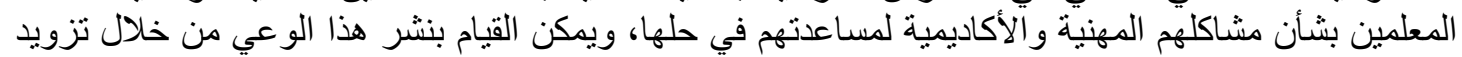

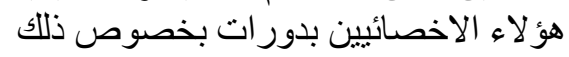

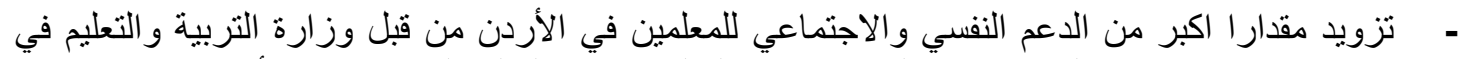

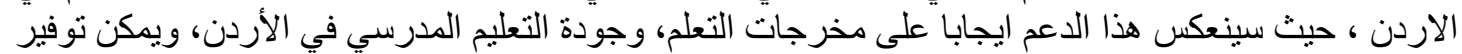

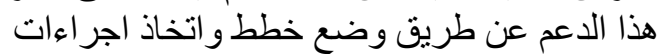

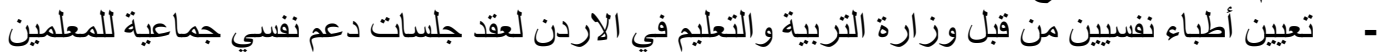

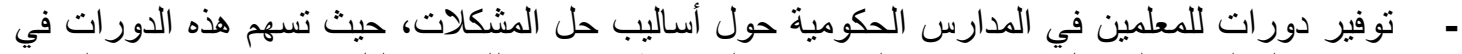

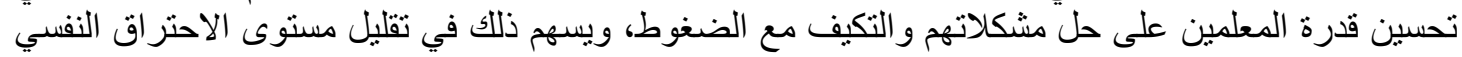
14. لايهم مقترحات للباحشين

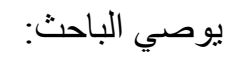
-بإجر اء در اسة تعمل على دراسة درجة الاحتر اقاق النفسي لدى المرشدين النفسيين في المدارس الحكومية الاردنية

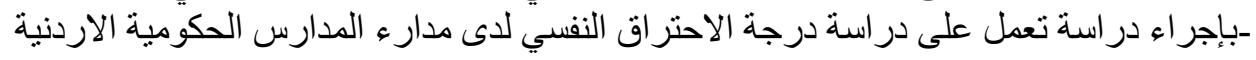

المراجع العربية 1. بطاينة، اسامة و الجوارنة، المعتصم بالله (2007). مستويات الاحتر اق النفسي لدى معلمي ومعلمات التربية

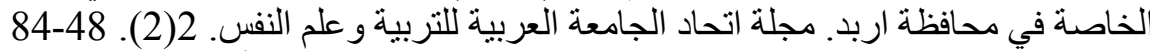

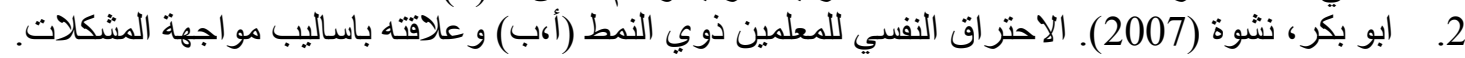

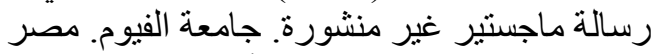

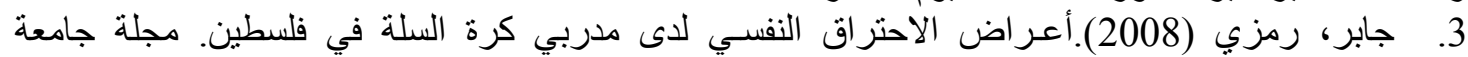

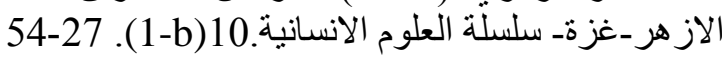

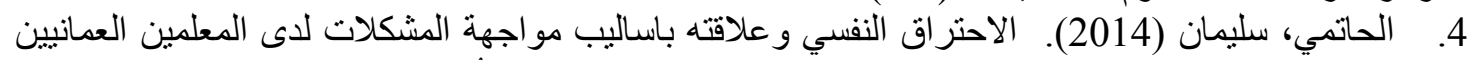

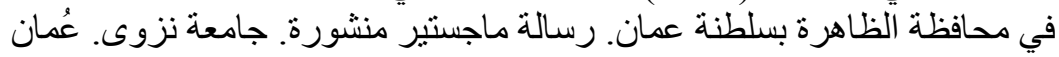

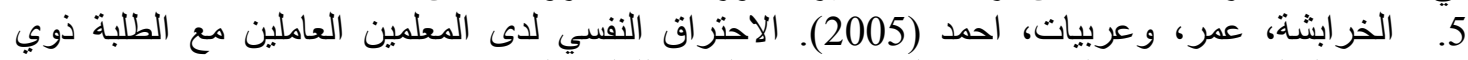

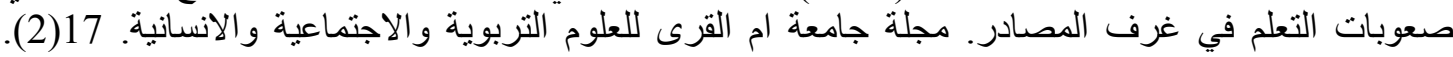
331-292

6. الخطيب، محمد جواد (2007). الاحتراق النفسي و علاقته بمرونة لدى المعلمين الفلسطنيين بمحافظة غزة. المؤتمر التربوي الثالث بغزة. اكتوبر، 2007، الأنراف 


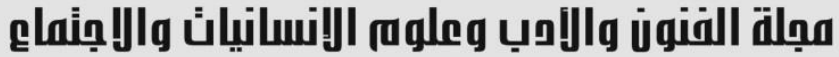

Journal of Arts, Literature, Humanities and Social Sciences www.jalhss.com

\begin{tabular}{|c|c|c|c|}
\hline$=\quad \approx$ & Volume (65) - March 2021 & العدد (65) - مارس 2021 & \\
\hline
\end{tabular}

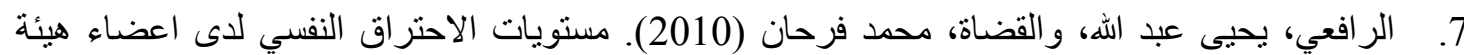
التدريس في كلية المعلمين بأبها في ضوء بعض المتغير ات. مجلة جامعة ام القرى للعلوم التربوية والنفسية. 2(2). $351-297$

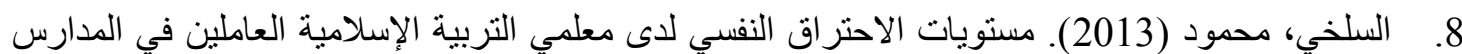

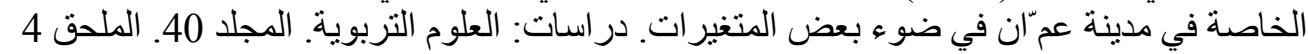

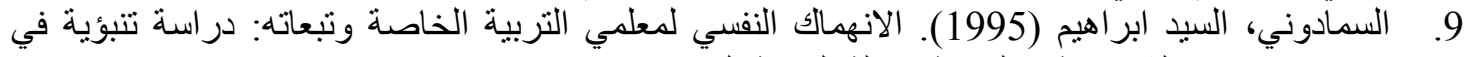

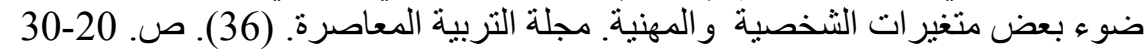

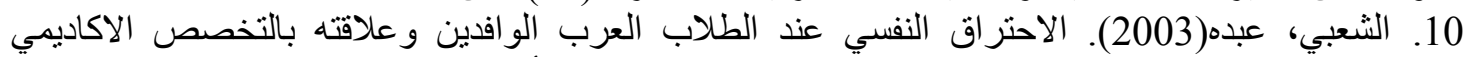

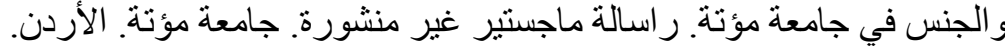

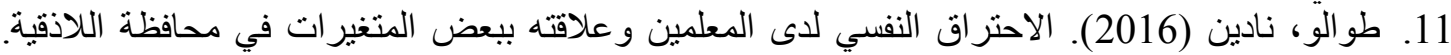

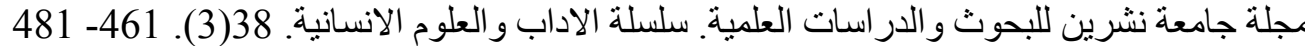

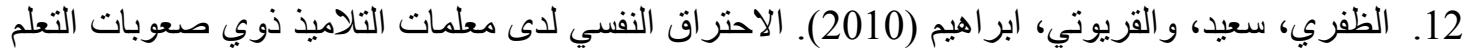

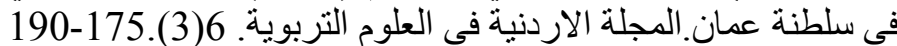
13. العرايضة، عماد (1916).

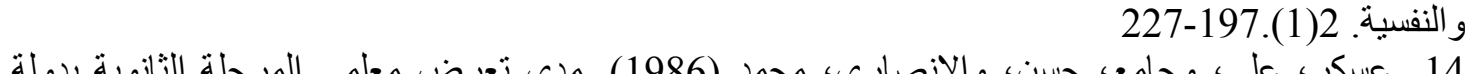

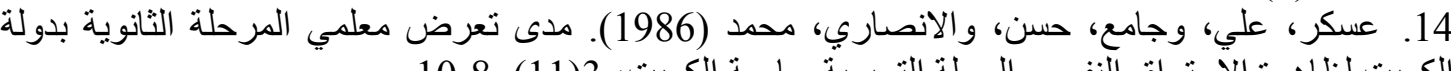

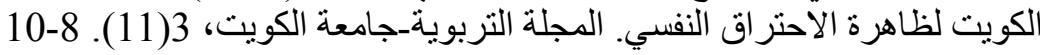

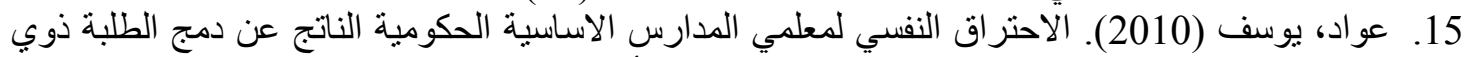
الاحتياجات الخاصة في الصفوف العادية. مجلة جامعة النجاح للأبحاث (العلوم الانسانية). 2002(9).

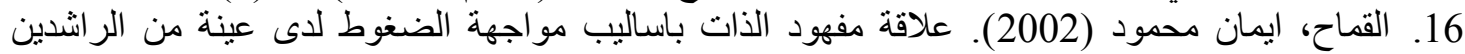

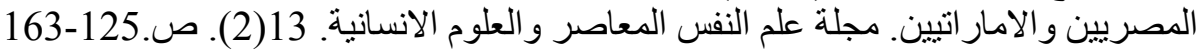

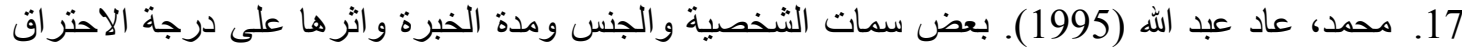

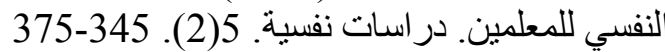
18. مسعود، سماهر (2010). ظاهرة الاحتراق الوظيفي لاى المان الموظفين الإداريين العاملين في وزارة التربية

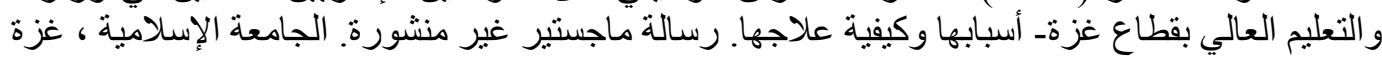

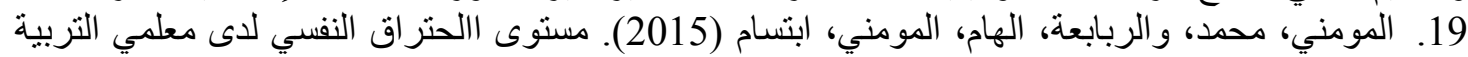

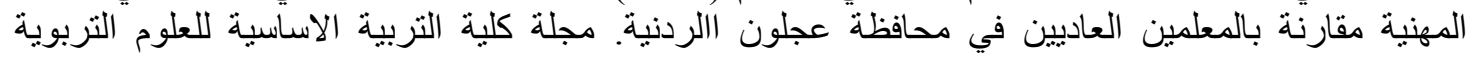

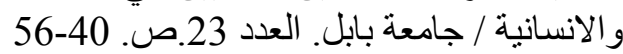

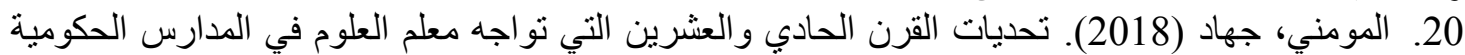

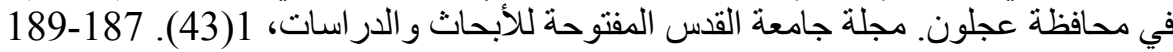

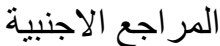

1. Aljbour, H. (2020). The Extent of Practicing Ethical Leadership by Public Secondary School Principals in Amman. The Journal of Education and Practice. 11(15). 57-63, DOI: 10.7176/JEP/11-15-07.

2. Branetti, G. (2001). Why do they teach? A study of Job satisfaction among longterm high school teachers. Teacher Education Quarterly. 28(3), pp.49-74

3. Maslach, S. \& Jackson, S. (1981). The measurement of experienced burnout. Journal of Occupational Behaviour. (2), 99-113

4. Melamed, S., Shirom, A., Toker, S., Berliner, S., \& Shapira, I. (2006). Burnout and risk of cardiovascular disease: evidence, possible causal paths, and promising research directions. Psychological bulletin, 132(3), 327-353. https://doi.org/10.1037/0033-2909.132.3.327 


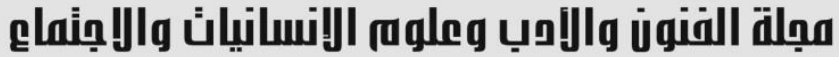

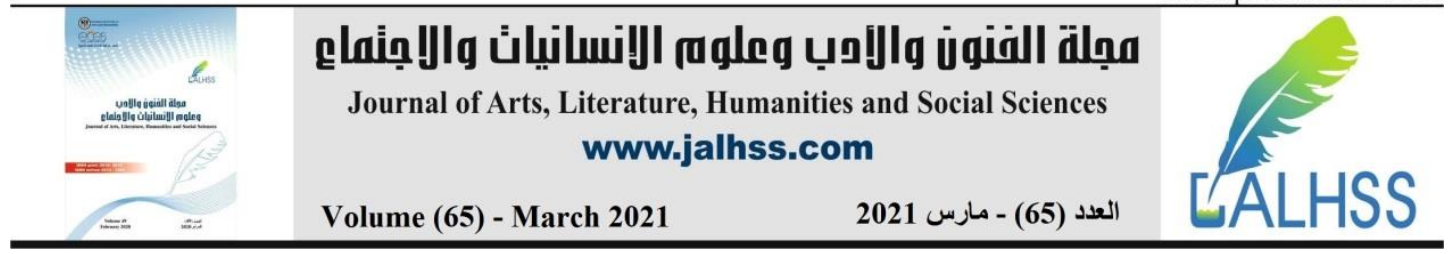

5. Nygaard, K. (2019). The Causes of Teacher Burnout and Attrition. Published MA Thesis, Concordia University, St. Paul. The United States

6. O'Brennan, L., Pas, E., \& Bradshaw, C. (2017). Multilevel examination of burnout among high school staff: Importance of staff and school factors. School Psychology Review, 46(2), 165-176. doi: 10.17105/SPR-2015-0019.V46-2

7. Richards, K. A. R., Hemphill, M. A., \& Templin, T. J. (2018). Personal and contextual factors related to teachers' experience with stress and burnout. Teachers and Teaching, 24(7), 768-787. doi: 10.1080/13540602.2018.1476337

8. Rožman, M., Treven, S., \& Cingula, M. (2018). The Impact of Behavioral Symptoms of Burnout on Work Engagement of Older Employees: The Case of Slovenian Companies. Naše gospodarstvo/Our Economy, 64(3), 3-11. DOI: 10.2478/ngoe-2018-0013

9. Salehi, M., \& Farhang, A. (2019). On the adequacy of the experimental approach to construct validation: the case of advertising literacy. Heliyon, 5(5), https://doi.org/10.1016/j.heliyon.2019.e01686

10. Schlichte, J., Yssel, N. and Merbler, J. (2005) Pathways to Burnout: Case Studies in Teacher Isolation and Alienation. Preventing School Failure: Alternative Education for Children and Youth, 50 (1), 35-40.

11. Shen, bo \& McCaughtry, Nate \& Martin, Jeffrey \& Garn, Alex \& Kulik, Noel \& Fahlman, Mariane. (2015). The Relationship Between Teacher Burnout and Student Motivation. British Journal of Educational Psychology. 85(4) Doi: 85. 10.1111/bjep.12089

12. Skaalvik, E. M., \& Skaalvik, S. (2017). Still motivated to teach? A study of school context variables, stress and job satisfaction among teachers in senior high school. Social Psychology of Education, 20, 15-37. Doi: 10.1007/s11218-016-9363-9 